\title{
Network connectivity, mechanical properties and cell adhesion for hyaluronic acid/PEG hydrogels
}

\author{
Sihem Ouasti ${ }^{a}$, Roberto Donno ${ }^{a}$, Francesco Cellesi ${ }^{b}$, Michael J. Sherratt ${ }^{a}$, Giorgio Terenghi ${ }^{a}$, \\ Nicola Tirelli ${ }^{\mathrm{a}, \mathrm{c}, *}$ \\ a School of Biomedicine, University of Manchester, Oxford Road, Manchester M13 9PL, United Kingdom \\ ${ }^{\mathrm{b}}$ School of Pharmacy, University of Manchester, Oxford Road, Manchester M13 9PL, United Kingdom \\ ${ }^{\text {c } S c h o o l ~ o f ~ M a t e r i a l s, ~ U n i v e r s i t y ~ o f ~ M a n c h e s t e r, ~ G r o s v e n o r ~ S t, ~ M 1 ~ 7 H S, ~ U n i t e d ~ K i n g d o m ~}$
}

\section{A R T I C L E I N F O}

\section{Article history:}

Received 3 May 2011

Accepted 12 May 2011

Available online 15 June 2011

\section{Keywords:}

Hyaluronic acid

Photopolymerization

Nanoindentation

Cell spreading

Fibroblasts

\begin{abstract}
A B S T R A C T
The study aimed to explore the influence of the network architecture on the mechanical properties and degradability of HA/PEG gels, and to highlight the relationship between Young's modulus and cell colonization with a selected architecture. Three different families of hyaluronic acid (HA)-based photopolymerized PEG diacrylate (PEGDA) hydrogels were compared, using different concentrations and molecular weights (64 and $234 \mathrm{kDa}$ ) of HA: semi-IPNs containing native HA in a PEG network (type I gels); co-networks obtained using thiolated HA as chain transfer agent during PEGDA polymerization (type II gels); co-networks obtained from the in situ preparation of a macromonomer derived from the Michael-type addition of thiolated HA on PEGDA (type III gels). From a comparative study of rheological properties and enzymatic degradability, type II gels were selected for a further study aiming to link their mechanical properties to cell spreading. Employing RGD-functionalized materials, Young's moduli were measured via AFM nanoindentation while the cell spreading behavior was quantitatively evaluated by monitoring morphology and metabolic activity (MTS assay) of L929 fibroblasts. By revealing a clear relation between increasing modulus and increasing cell spreading/proliferation, the study showed the possibility to fine tune the cell/material interactions with appropriate reactive processing techniques.
\end{abstract}

(c) 2011 Elsevier Ltd. All rights reserved.

\section{Introduction}

Hyaluronic acid (HA) is a glycosaminoglycans (GAG) composed by alternating repeating subunits of $\mathrm{D}$-glucuronic acid and $\mathrm{N}$-acetylD-glucosamine, which naturally occurs in virtually in all animals and many bacteria. In common to most GAGs, HA is found primarily in extracellular and pericellular matrices, although a few studies have also shown intracellular and even nuclear localization [1,2], it is strongly hydrated, biocompatible and non-immunogenic; in contrast to other GAGs, HA is not sulfated and can reach very large molecular weights. These features, and its easy degradability by mammalian enzymes (hyaluronidases), have boosted the use of HA in biomedicine, most commonly as a filler in cosmetics or as a matrix component/viscosupplementation element in regenerative medicine. A number of functional HA derivatives have also

\footnotetext{
* Corresponding author. School of Biomedicine, University of Manchester, Oxford Road, Manchester M13 9PL, United Kingdom. Tel.: +44 16127524 80; fax: +44 161 2752396.

E-mail address: nicola.tirelli@manchester.ac.uk (N. Tirelli).
}

been developed, in order to modulate its biological properties (e.g. enzymatic degradability through esterification as in HYAFF derivatives) and/or to prepare biomimetic 3D-extended matrices (e.g. hydrogels [3]) or dispersible materials (e.g. nanoparticles [4]).

We will here specifically focus on in situ gellable HA formulations, which have found vast application in tissue engineering [5,6], where HA not only provides a cell-degradable matrix, but may also contribute to the controlled delivery of biologically active payloads, such as basic fibroblast growth factor [7], or BMP-2 [8].

HA is most popularly derivatized at the glucuronic acid carboxy groups. They can be directly employed for chemical cross-linking [9], but more commonly they are transformed into groups that later allow triggered in situ and possibly in vivo cross-linking events. Specifically, the carboxy groups can be converted in: A) amines or aldehydes, which react respectively with low MW diamines or dialdehydes to produce hydrogels through Schiff base formation, [10,11]. B) Thiols, which can perform Michael-type addition on diacrylates or other Michael-type acceptors [12], nucleophilic substitutions on haloacetates [13], or can be dimerized to disulfides [14]. C) (Meth)acrylic residues, that are later photopolymerized with free radical mechanism [15-18] or react with low 
MW multithiols through Michael-type addition [8]. D) Azides or alkynes to produce a cross-linking through Huygens "click" reactions [19]. E) Phenols (tyramines) that spontaneously cross-link after their enzymatic oxidation to catechols [20]. Generally, the techniques mentioned above preserve a substantial sensitivity of HA to the action of hyaluronidases, thus allowing the enzymemediated degradation of the hydrogels [16,21].

We are specifically interested in photopolymerization. This is a widespread method for the in situ preparation of tissue engineering matrices, whose biocompatibility and efficacy have been demonstrated in a number of studies [22-25]. Photopolymerization has been used for the preparation of HA/poly(ethylene glycol) (PEG) systems, whose degradability and mechanical properties can be controlled in a relatively independent fashion, respectively through the HA and PEG content and molecular weight. Two systems have been quite widely investigated: co-networks, i.e. cross-linked copolymeric networks of polymerizable HA derivatives and PEG diacrylate (PEGDA), and semi-interpenetrated networks (semiIPNs), which contain physically entrapped non-functional (native) HA in a covalent network of photopolymerized PEGDA.

These photopolymerized HA/PEG combinations are safe for in situ gelation in the presence of cells. In a recent thorough study, the group of Henninck and Alblas (2009) focused on the effects that the preparation of co-networks of methacrylated HA and PEGDA may have on the cell cycle, apoptosis and osteogenic differentiation of embedded stem cells. The research showed that the photopolymerization did not harm embedded stem cells or had no impact on their ability to undergo osteogenic differentiation; further, it was suggested that the HA/PEG macroradicals preferentially react with acrylates rather than with any constituent of cellular membranes [26]. HA/PEGDA semiIPNs have been successfully used by the group Elisseeff (2000) for chondrogenic differentiation and cartilage tissue engineering [27,28] and this has resulted in the development of the ChonDux materials (Cartilix, now Biomet) for cartilage reconstruction.

In a previous work [17], we have compared methacrylated HA/ PEGDA co-networks with semi-IPNs; both systems contained a high amount (10 wt.\%) of HA, and lower amounts of PEGDA (2 or 5 wt.\%). The modulus $\left(\mathrm{G}^{\prime}\right)$ of the co-networks was higher, due to their higher cross-link density; both types of hydrogels were susceptible to enzyme-induced degradation, but the degradability was greater for the co-networks and decreased with increasing PEGDA content. The large HA content caused a marked sensitivity to hyaluronidase, even when the covalent network of the semi-IPNs did not incorporate enzymatically degradable groups (semi-IPNs). On the other hand, high HA amounts are not well suited for practical applications, due to the cost of the starting material and the high viscosity of the precursor solutions. Furthermore, the high HA concentrations may not be necessary: the group of Webb (2007) has clearly shown that small amounts of HA may be sufficient to improve cell motility and cellmediated degradability of an artificial matrix [29].

Here we have focused on low HA content materials, with the aim, first, of studying the influence that the connectivity between network components may have on the mechanical properties and degradability of the hydrogels. Both factors influence cell phenotype and migration in a 3D matrix [30-32]. Second, of selecting a network architecture on the basis of the above analysis and assess the relationship between its mechanical properties and cell spreading/proliferation.

Specifically, we have focused on three different hydrogel types (Scheme 1$)$, which were all based on PEGDA $\left(\overline{M_{n}}=575\right.$ Da, 5 wt.\%) and HA ( 64 or $234 \mathrm{kDa}$ ), the latter used at three different concentration $(0.5,1.0$ and $2.0 \mathrm{wt} . \%)$ in a native or thiolated form:

Type I gels: semi-IPNs obtained from native HA entrapped in a network of photopolymerized PEGDA. During photopolymerization the materials are likely to phase-separate into HA-rich and PEGDA- rich domains (Scheme 2, top left), due to the increasing incompatibility of PEG and HA with increasing molecular weight. Enzymatic degradation would be possible only in the HA domains.

Type II gels: co-networks obtained from the use of thiolated HA (HA-SH) as a chain transfer agent: thiyl radicals are formed during polymerization and effectively act as initiators for PEGDA. The use multifunctional thiols is well known in acrylate photopolymerization [33] and thiols have also been employed in PEGDA photoinitiated polymerization to introduce various peptides in the network structure [34]. In these gels HA would be covalently bound to the PEG network, but HA thiyl radicals may also intra- or intermolecularly recombine in form of disulfides. As a result, some form of phase separation in PEG- and HA-rich domains is still possible, the latter possibly kept together by disulfide bonds (Scheme 2, top right). Due to the (partial) integration of HA in the PEGDA network, the construct should show sensitivity to hyaluronidase, although complete degradation may not be achieved.

Type III gels: co-networks obtained using an in situ generated HA macromonomer. By incubating HA-SH with an excess of PEGDA at slightly basic $\mathrm{pH}$, the Michael-type addition produces an HA macromonomer with dangling and acrylate-terminated PEG chains. The polymerization of these chains will allow the integration of HA within the PEGDA network (Scheme 2, bottom right), making the hydrogel structure enzymatically degradable.

\section{Experimental section}

\subsection{Materials}

HA sodium salt with $\overline{M_{w}} 64$ or $23^{4} \mathrm{kDa}$ was purchased from Medipol (SA, Lausanne). N-(3-dimethylpropyl)-N-ethylcarbodiimide hydrochloride (EDC), triethanolamine and cysteamine were purchased from Fluka (St-Louis, MO). HEPES, $N$-vinyl pyrrolidone (NVP), Eosin Y, Tris(2-carboxyethyl)phosphine (TCEP), 5,5'-dithiobis(2nitrobenzoic acid) (DNTB) were bought from Sigma (St-Louis, MO) and used without further purification. Poly(ethylene glycol) diacrylate (PEGDA) with $\overline{M_{n}}=575 \mathrm{Da}(\mathrm{g} /$ $\mathrm{mol}$ ) was purchased from Sigma (St-Louis, MO); inhibitors were removed via elution in dichloromethane through hydroquinone monomethyl ether (MEHQ) remover disposal pre-packed columns (Sigma) prior to polymerization experiments.

GCGRGDS peptide was synthesized using solid phase peptide synthesis; the resin, amino acids and activator (HCTU) were purchased from Merck (Gibbstown, NG). Ovine testis hyaluronidase was bought from Calbiochem (Gibbstown, NG). Phosphate buffer saline tablets were purchased from Oxoid (Basingstoke, UK).

Dodecane was bought from Thermo fisher scientific (Loughborough, UK).

The MTS [3-(4,5-dimethylthiazol-2-yl)-5-(3-carboxymethoxyphenyl)-2-(4sulfophenyl)-2H-tetrazolium] kit was bought from Promega (Madison, WN). Dulbecco's modified eagle medium (DMEM), the antibiotic-antimycotic solution and the Quantipro BCA assay kit were purchased from sigma (St-Louis, MO), fetal bovine serum (FBS) and L-glutamine from Invitrogen (Paisley, UK). L929 murine fibroblasts were purchased from Sigma (St-Louis, MO), and used at early passages (P4-P15).

\subsection{Preparative procedures}

\subsubsection{Thiolated HA (HA-SH)}

$1 \mathrm{~g}$ of sodium HA $\left(2.5 \mathrm{mmol}\right.$ of carboxy group, $\left.\overline{M_{w}}: 64,234 \times 10^{3} \mathrm{~g} / \mathrm{mol}\right)$ was dissolved in $100 \mathrm{~mL}$ of distilled water, to which EDC $(0.5 \mathrm{mmol})$ and cysteamine $(0.25 \mathrm{mmol})$ were added under slow stirring. The $\mathrm{pH}$ was adjusted to 5.3 by the addition of $1 \mathrm{~m} \mathrm{NaOH}$. The solution was left to incubate for $2 \mathrm{~h}, \mathrm{pH} 5.3$. At the completion of the incubation, the same amount of EDC and cysteamine were added, the $\mathrm{pH}$ readjusted like previously described and incubated for another $2 \mathrm{~h}$, under the same conditions [17]. The solution was then transferred to dialysis membranes (MW cut-off $=25 \mathrm{kDa})$ and dialyzed against distilled water containing TCEP $(0.25 \mathrm{~mm}$, corresponding to a1:0.1 thiol/TCEP molar ratio in the dialysis bag) under nitrogen for three days, and against distilled water and under nitrogen for one day (resistance of dialysis water $2 \mathrm{~m} \Omega \mathrm{cm}$ ) and then freeze dried to yield $0.75-0.80 \mathrm{~g}$ of a white solid. Degree of thiolation: $16 \mathrm{~mol} \%$ for both molecular weights, assessed using the Ellman's method [35] (molar concentration of thiol groups calculated using a calibration of cysteamine, see Supplementary data, Fig. 1Sd) and ${ }^{1} \mathrm{H}$ NMR (cysteamine signal at $2.8 \mathrm{ppm}\left(-\mathrm{CH}_{2}\right.$ in $\alpha$ to the amide) vs. HA signal at $1.9 \mathrm{ppm}$ (N-acetyl methyl group)). The same thiol content was recorded at the end of the dialysis and after freeze drying.

${ }^{1} \mathrm{H}$ NMR $\left(\mathrm{D}_{2} \mathrm{O}\right): \delta=4.4(\mathrm{H} 7), 4.3(\mathrm{H} 1), 3.8(\mathrm{H} 6), 3.2-3.7(\mathrm{H} 2-\mathrm{H} 5, \mathrm{H} 8-11), 2.7$ (H13), 1.90 ppm (H-12) (See Fig. 1). 


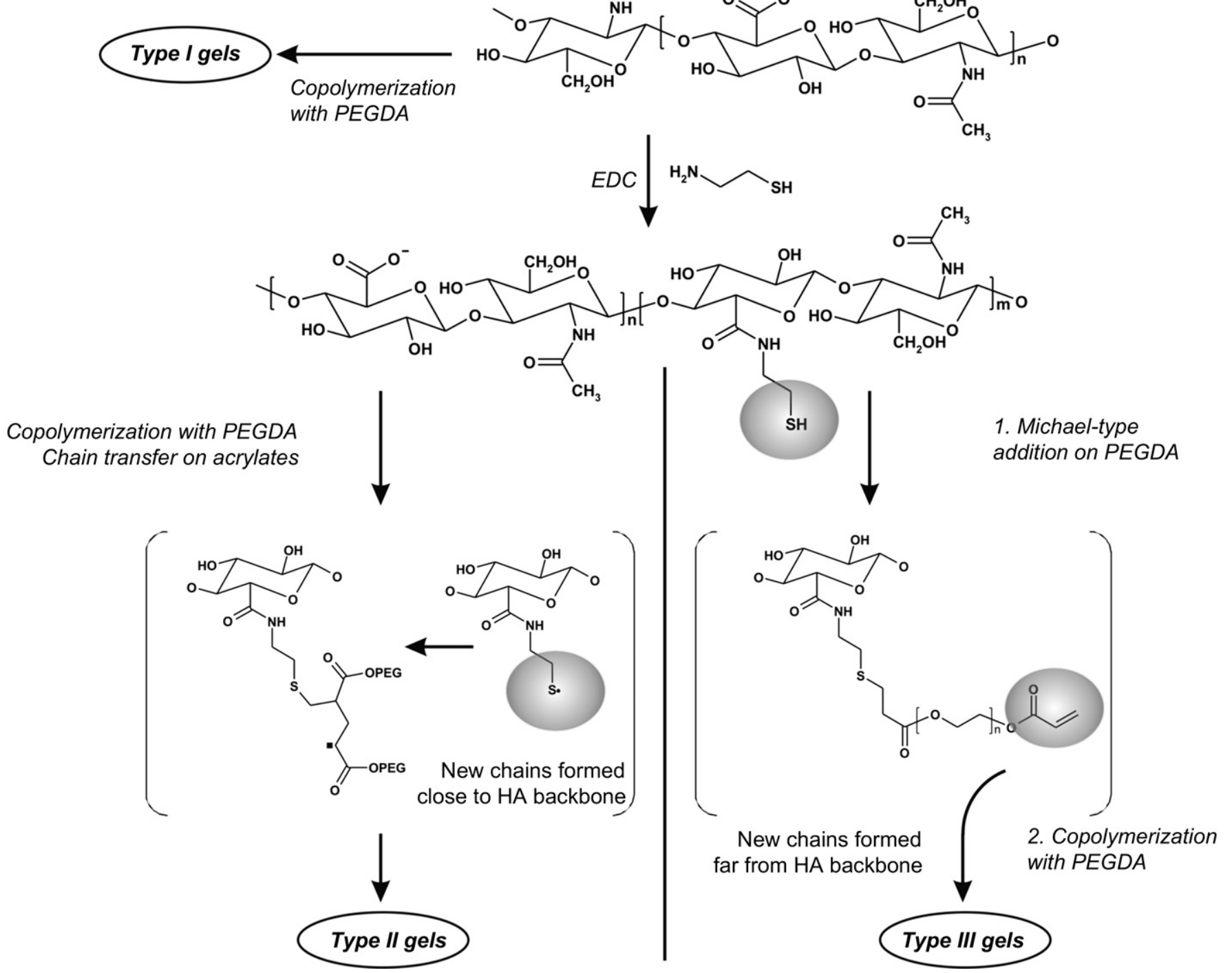

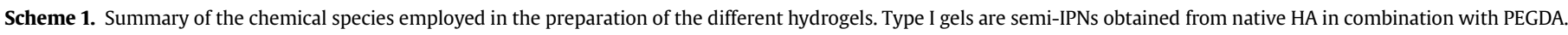

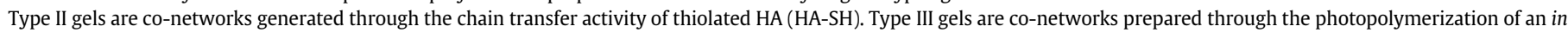
situ generated HA-PEGDA macromonomer with PEGDA itself.

\subsubsection{Photopolymerization experiments}

Precursor solutions were prepared as follows:

2.2.2.1. PEGDA reference gels. The cystein-containing MeOGCGRGDSNH $\mathrm{H}_{2}$ peptide (28 mg, $0.043 \mathrm{mmol}$ of thiol groups) was dissolved in $3.5 \mathrm{~mL}$ of Hepes buffer (normal saline, pH 7.4), containing TCEP (62 $\mathrm{mg}, 0.215 \mathrm{mmol}$ ) in a 1:5 thiol/TCEP ratio and triethanolamine $(7.5 \mathrm{mg}, 0.5 \mathrm{mmol})$. PEGDA was added dropwise to the mixture adjusting the $\mathrm{pH}$ to 7.4 with $1 \mathrm{M} \mathrm{NaOH}$, to provide a final 1:20 thiol/acrylate ratio ( $250 \mathrm{mg}$ of PEGDA, $0.87 \mathrm{mmol}$ of acrylate groups). The solution was incubated for $2 \mathrm{~h}$ at room temperature to allow the Michael-type reaction to occur, then $500 \mu \mathrm{L}$ of a $10 \mathrm{~mm}$ solution of Eosin Y (corresponding to $5 \mu \mathrm{mol}$ of Eosin $\mathrm{Y}$ ), and $50 \mathrm{mg}$ of NVP $(4.5 \mathrm{mmol})$ were added, adjusting the volume to $5 \mathrm{~mL}$.

2.2.2.2. Type I gels (semi-IPNs). Appropriate amounts $(5,10$ or $20 \mathrm{mg}$ ) of solid HA $\left(\overline{M_{w}}: 64,234 \times 10^{3} \mathrm{~g} / \mathrm{mol}\right)$ were added to solutions containing the peptide, TCEP, PEGDA, triethanolamine, eosin Y and NVP (total volume $=1 \mathrm{~mL}, \mathrm{pH}=7.4$ ) prepared as described above to yield HA concentrations of $0.5,1$ and $2 \mathrm{wt} . \%$. The mixture was stirred for $30 \mathrm{~min}$, the $\mathrm{pH}$ was adjusted to 7.4 with $1 \mathrm{~m} \mathrm{NaOH}$ (the $\mathrm{pH}$ could drop as low as 6.5 in the samples with higher HA concentration).

2.2.2.3. Type II gels (covalently connected networks). The procedure described for type I gels was followed also for gels containing identical amounts of HA-SH. The presence of disulfides in HA-SH in the polymerization mixture is assumed negligible (see above).
2.2.2.4. Type III gels (incubated, covalently connected networks). The procedure used for type I and type II gels was modified, adjusting the $\mathrm{pH}$ to 8.4 after the addition of the appropriate amounts of HA-SH and allowing the Michael-type addition to proceed for $2 \mathrm{~h}$ at room temperature. The $\mathrm{pH}$ of the solution was finally adjusted to 7.4 with $1 \mathrm{~m} \mathrm{HCl}$

The precursor solutions were filtered $(0.2 \mu \mathrm{m})$ and appropriate amounts were transferred to be photopolymerized in a shear rheometer (see Physico-chemical characterization/Rheology), in 24-well Transwell plates (see Physico-chemical characterization/Swelling), or in 96-well plates (see Biological characterization/2D cell culture on hydrogels).

\subsection{Physico-chemical characterization}

\subsubsection{Molecular characterization}

${ }^{1} \mathrm{H}$ NMR spectra were recorded on freeze dried samples re-dissolved in $\mathrm{D}_{2} \mathrm{O}$ at a concentration of $1 \mathrm{wt} . \%$, using a Bruker AC-300 MHz spectrometer. FT-IR spectra were recorded in ATR mode (Golden gate) on a Tensor 27 Bruker spectrometer.

\subsubsection{Rheology}

A Gemini Advanced Rheometer (Malvern, UK) with a parallel plate configuration (25 mm upper plate diameter) was used to record loss $\left(G^{\prime \prime}\right)$ and storage $\left(G^{\prime}\right)$ modul (shear stress $=0.1 \mathrm{~Pa}$, frequency $=1 \mathrm{~Hz}$, temperature $=37^{\circ} \mathrm{C}$ ). A hollow lower plate equipped with a $5 \mathrm{~mm}$-thick transparent quartz sample support was employed, in 


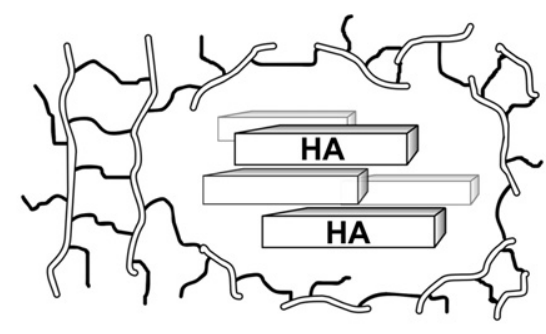

Type I gels

Incompatible HA and PEG phases

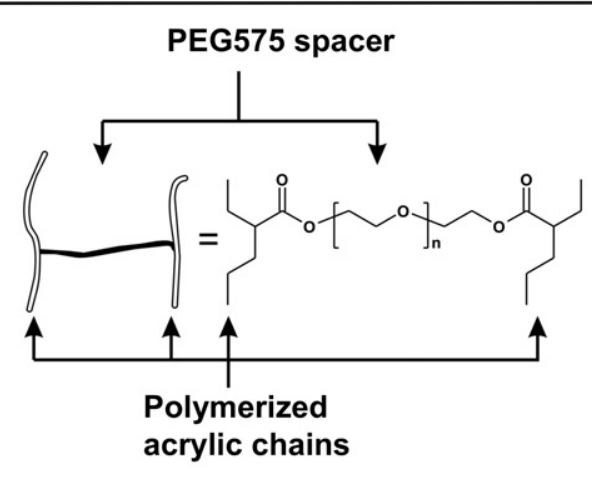

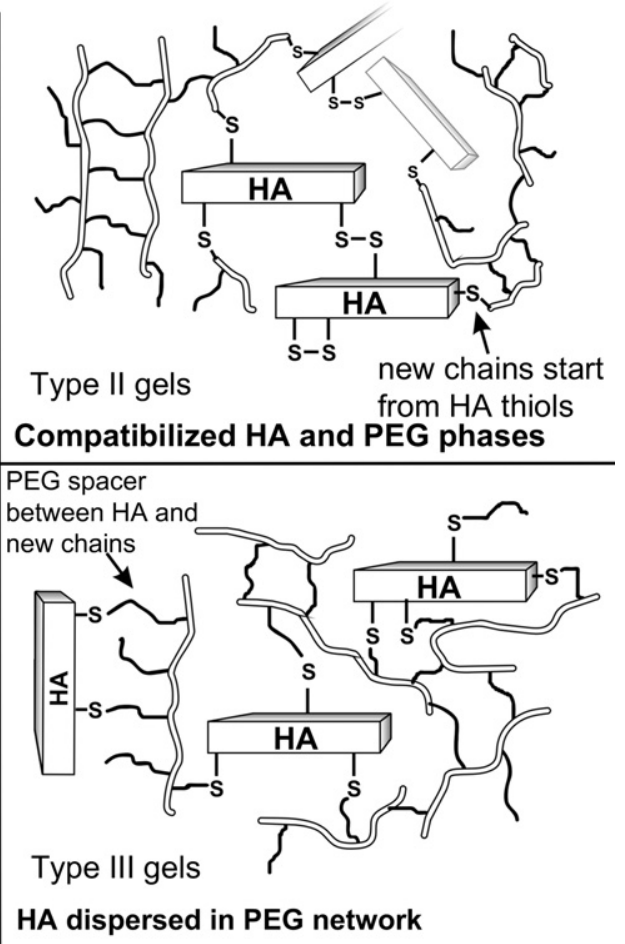

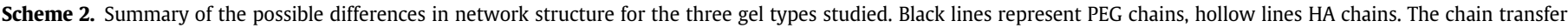

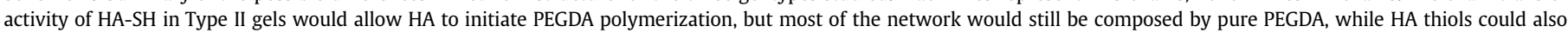
combine between themselves into disulfides: as a result, it is possible that type II gels would resemble more a "compatibilized blend" rather than a homogeneous network.

order to allow illumination of the sample from bottom (see Supplementary data, Fig. 2Sd). An Omnicure S1000 lamp (Exfo, Mississauga, ON, Canada, filtered to provide emission in the range $400-500 \mathrm{~nm}$ ) was connected to a liquid-core optical fiber $(\varnothing=5 \mathrm{~mm})$ terminating with a collimator $(\varnothing=25 \mathrm{~mm})$; an output power of $2 \mathrm{~W} / \mathrm{cm}^{2}$ was recorded at the end of the fiber, which was estimated to correspond to $70 \mathrm{~mW} / \mathrm{cm}^{2}$ after the collimator. For all photopolymerization experiments, $50 \mu \mathrm{L}$ of solution were deposited on the quartz sample holder lowering the upper plate down to a gap of $0.1 \mathrm{~mm}$, covered with dodecane to minimize water evaporation and finally illuminated for $500 \mathrm{~s}$.

\subsubsection{Swelling experiments}

$100 \mu \mathrm{L}$ of precursor solutions were deposited in 24-well Corning Transwells and then irradiated for $1000 \mathrm{~s}$ (Omnicure S1000 lamp connected to a liquid-core optical fiber with $\varnothing=5 \mathrm{~mm}$ and output power of $78 \mathrm{~mW} / \mathrm{cm}^{2}$, distance hydrogel surface/ optical fiber $\sim 5 \mathrm{~mm}$ ). The hydrogel-containing Transwells were placed in 24-well plates containing $500 \mu \mathrm{L}$ of 0.5 wt.\% $\mathrm{NaN}_{3}$ in $10 \mathrm{~mm}$ PBS; the same volume of buffer was added on top of the gels, which were incubated under these conditions at $4{ }^{\circ} \mathrm{C}$, recording their weight immediately after photopolymerization $\left(W_{0}\right)$, and then at a time $t=1,2,4,6,22$, and $24 \mathrm{~h}$ after the start of incubation $\left(W_{t}\right)$. See Supplementary data (Fig. 4Sd) for an overview of the swelling ratio $W_{t} / W_{0}$ as a function of time. The swelling ratios when constant weight was achieved $\left(W_{\infty} / W_{0}\right)$ were taken as a measure of equilibrium swelling in PBS. The hydrogels pre-swollen in $10 \mathrm{~mm}$ PBS buffer for $24 \mathrm{~h}$ were further incubated in sterile deionized water for $24 \mathrm{~h}$ at $37{ }^{\circ} \mathrm{C}$, after which their weight were recorded.

The presence of elastically active disulfide bridges was assessed measuring the swelling ratio after incubation in buffers containing TCEP in 5-fold molar excess to the overall amount of thiols $(6.25-25 \mu \mathrm{mol})$.

\subsubsection{Degradation experiments}

Hydrogels prepared as described in the "Swelling" section were incubated in Transwells at $37{ }^{\circ} \mathrm{C}$ for $24 \mathrm{~h}$ in $0.5 \mathrm{wt}$.\% $\mathrm{NaN}_{3} \mathrm{PBS}$; the equilibrium-swollen weight $\left(W_{0}{ }^{e q}\right)$ was recorded at the end of the incubation period. The hydrogels were then exposed to $0.5 \mathrm{wt} . \% \mathrm{NaN}_{3}$ PBS containing $200 \mathrm{U} / \mathrm{mL}$ of ovine testis hyaluronidase; the solution was replaced every day to ensure the presence of active enzyme throughout the time span of the study. The weight of the gels was then recorded as a function of time $\left(W_{t}^{e q}\right)$.

\subsubsection{Nanoindentation}

Nanoindentation studies were performed in a closed humidified environment in a Molecular Force Probe 3D AFM (model MFP-3D, Asylum Research, Santa Barbara, CA, USA) equipped with a Bio-Heater ${ }^{\mathrm{TM}}$ at a temperature of $25^{\circ} \mathrm{C}$. The humidity within the Bio-Heater ${ }^{\mathrm{TM}}$ was kept constant through the presence of HEPES buffer soaked paper. Silicon nitride cantilevers (model MLCT, Veeco, Santa Barbara, CA) with nominal spring constants, tip radii, tip heights and resonant frequencies of $0.1 \mathrm{~N} / \mathrm{m}, 20 \mathrm{~nm}, 2.5-8.0 \mu \mathrm{m}$ and $38 \mathrm{kHz}$, respectively, were utilized in all measurements. The resonant frequency and spring constant of each cantilever were determined by the thermal noise method [36]; typical values of spring constant and drive frequency are $0.14 \mathrm{~N} / \mathrm{m}$ and $37.7 \mathrm{kHz}$, respectively.

In order to convert force-displacement measurements into force-indentation dependences, the deflection sensitivity of the instrument was calculated from measurements on borosilicate glass coverslips. For all nanoindentation curves, the indentation rate was $300 \mathrm{~nm} / \mathrm{s}$ and the maximum force applied on the hydrogel surface was $10 \mathrm{nN}$.

The Young's modulus values were calculated by fitting the force-indentation data with the Hertz cone model (also known as Hertz-Sneddon model) [37] $F=(2 / \pi) E^{*} h^{2} \tan \alpha$, where $F$ is the load, $h$ the displacement of the specimen surface, $\alpha$ is the half opening apex-angle of the tip and $E^{*}$ is the combined modulus [38]; the latter is defined as $\frac{1}{E^{*}}=\frac{\left(1-v_{s}^{2}\right)}{E_{s}}+\frac{\left(1-v_{t}^{2}\right)}{E_{t}}$, where $E_{s}, v_{s}$ and $E_{t}, v_{t}$ are the Young's moduli and the Poisson's ratios for the sample and the tip, respectively. For all measurements: $E_{t}=290 \mathrm{GPa}, v_{t}=0.25, h=200 \mathrm{~nm} \alpha=25^{\circ}$ and $v_{s}=0.45$ [39]. Five indentation curves were collected for each sample at random positions on the substrate.

In order to assess the homogeneity of the hydrogel surfaces, force maps were acquired for each sample, performing 16 indentation curves within a $10 \mu \mathrm{m} \times 10 \mu \mathrm{m}$ area at a lateral separation of $2.5 \mu \mathrm{m}$.

\subsection{Biological characterization}

\subsubsection{HA-SH cytotoxicity}

Murine L929 fibroblasts were seeded (5000 cells/well) in a 96-well plate, cultured in DMEM medium containing $10 \%$ FBS, $1 \%$ antibiotic/antimitotic solution, and $1 \%$ L-glutamate (full medium) and incubated for $24 \mathrm{~h}$ under standard sterile conditions for cell culture $\left(5 \% \mathrm{CO}_{2}, 37{ }^{\circ} \mathrm{C}\right)$. HA or HA-SH [MW: $64,234 \mathrm{kDa}$ ] were solubilized at different concentrations $(0-2 \mathrm{wt} . \%$, the high viscosity of the preparation precluded investigations at higher HA concentrations) in full DMEM medium and added to the cells after washing them with ice-cold PBS. The murine fibroblasts were then incubated for $24 \mathrm{~h}$ under standard sterile conditions. At the completion of the incubation, the cells were washed and incubated further for $2 \mathrm{~h}$ in plain medium containing MTS. The cytotoxicity was measured using a colorimetric method based on the bioreduction of MTS (3-(4,5-dimethylthiazol-2-yl)-5-(3-carboxymethoxyphenyl)-2-(4sulfophenyl)-2H-tetrazolium), into a colored formazan, which is soluble in full medium. The quantity of formazan produced as measured by the absorbance at 
native unit
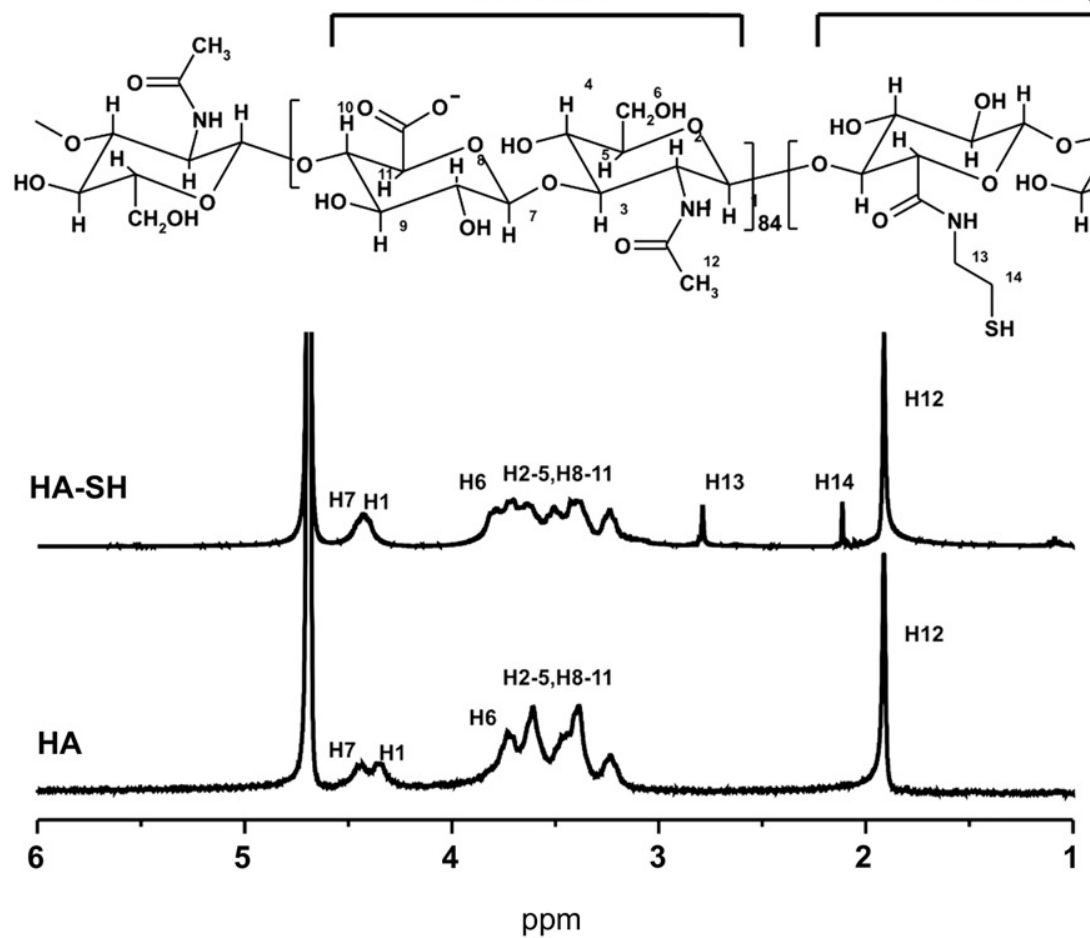

thiol-bearing unit

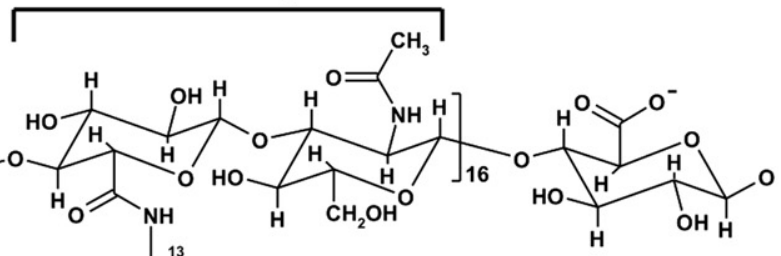

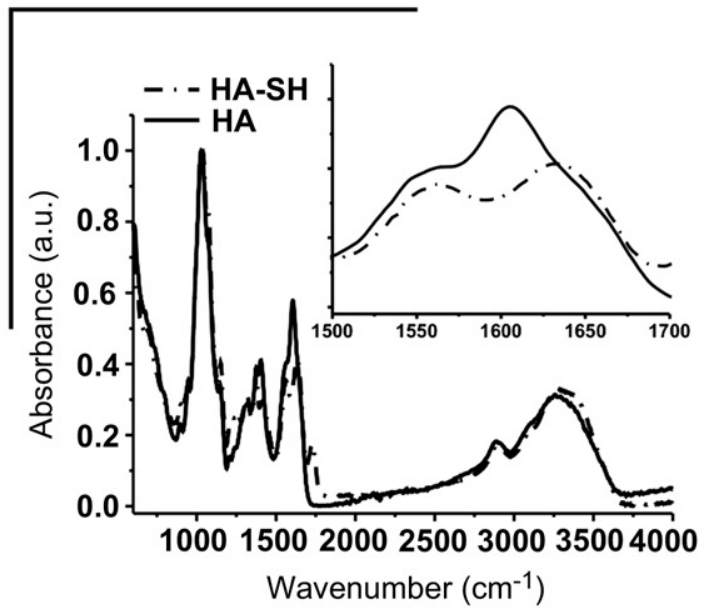

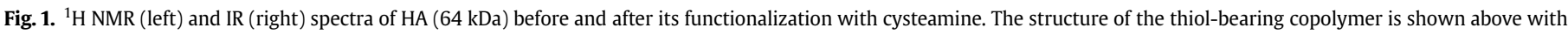

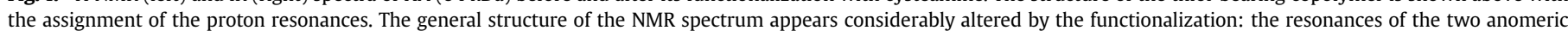

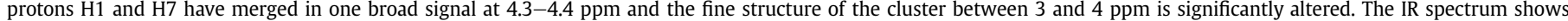
a significant decrease of the peak at $1610-1620 \mathrm{~cm}^{-1}$, which can be associated to the HA carboxy groups, and an increase in the amide I band.

$490 \mathrm{~nm}$ is proportional to both the number and the metabolic activity of living cells in culture. MTS solution was diluted at $5 \%(\mathrm{v} / \mathrm{v})$ in serum free medium (plain medium), and the resulting solution was transferred into the wells containing the cells preincubated with HA or HA-SH containing full medium, after being washed with icecold PBS. The cells were then incubated further for $2 \mathrm{~h}$ in standard conditions for cell culture. The absorbance readings were acquired with the Synergy2 Biotek platereader using Gen5 software, after which, the total protein content was quantified using the Quantipro BCA assay kit. Briefly, the cells were washed with ice-cold PBS, and incubated for $15 \mathrm{~min}$, in $100 \mu \mathrm{L}$ cell lysis buffer (0.5\% triton X-100 in PBS), to which $100 \mu \mathrm{L}$ of Quantipro solution (prepared following the instructions of the manufacturer) was added. After $1 \mathrm{~h}$ incubation at $60^{\circ} \mathrm{C}$, the absorbance was recorded. The cytotoxicity measurements were then normalized by the amount of total protein content in each well.

\subsection{2. $2 D$ cell culture on hydrogels}

$60 \mu \mathrm{L} /$ well of precursor solutions were deposited in wells of a 96-well plate and then irradiated for $600 \mathrm{~s}$ (Omnicure S1000 lamp connected to a liquid-core optical fiber with $\varnothing=5 \mathrm{~mm}$ and output power of $78 \mathrm{~mW} / \mathrm{cm}^{2}$, distance hydrogel surface/ optical fiber $\sim 5 \mathrm{~mm}$ ). The gels were swollen in $10 \mathrm{~mm}$ PBS for $24 \mathrm{~h}$ and washed four times with PBS during additional $24 \mathrm{~h}$. L929 murine fibroblasts incubated for $24 \mathrm{~h}$ in standard conditions for cell culture were trypsinized and seeded at a density of 5000 cells/well on the hydrogels. The cells were cultured in full DMEM, in sterile standard conditions for cell culture $\left(5 \% \mathrm{CO}_{2}, 37^{\circ} \mathrm{C}\right)$ for 9 days; the medium was replaced every two to three days. The relationship between spreading behavior and substrate properties has often been studied at day 1 [40]; in our case, even on the most adhesive gels, fibroblasts did not reach a fully spread spindle-like phenotype before day 2 , due to the relatively poorly adhesive character of the PEG/HA gels; we have therefore compared different substrates only from day 3 onward.

Cell area, cell circularity, cell count. We have here adopted the definition of circularity as a dimensionless parameter, that is, $4 \pi(($ area $) /($ perimeter 2$)$ ), which is equal to 1 for a perfect circle while approaching zero for very elongated shapes, rather than the analogous shape factor $f$ defined as the perimeter/area ratio, which has the dimensions of the reciprocal of a length $[41,42]$. Phase contract pictures taken at day 3 were thresholded generating a binary image with a white background and black cells; cell area, cell circularity and surface coverage were measured (typically on an average of 150-200 cells) using the analyze particles facility in Image J. The average cell count was obtained from surface coverage data dividing them by the average cell area and normalizing them against the figure obtained for TCPS.

Proliferation. Cell proliferation was assessed using the MTS (3(4,5-dimethylthiazol-2-yl)-5-(3-carboxymethoxyphenyl)-2-(4-sulfophenyl)- $2 \mathrm{H}$ - tetrazolium) assay. Briefly, on day 3,6 and 9 after the cell seeding, the fibroblasts were washed and incubated for $2 \mathrm{~h}$ with plain medium containing 5\% MTS in sterile standard conditions for cell culture. The medium was then transferred to a new 96-well plate and the absorbance was measured with $\lambda=490 \mathrm{~nm}$. The proliferation of the cells on the hydrogels was compared to the one on TCPS.

\section{Results and discussion}

\subsection{Preparation and cytotoxicity of thiolated $H A(H A-S H)$}

Thiol groups were introduced on hyaluronic acid (MW $=64$ and $234 \mathrm{kDa}$ ) using a standard carbodiimide-mediated reaction of the HA carboxylic groups with the amine group of cysteamine. The reaction product (HA-SH) presented typical ${ }^{1} \mathrm{H}$ NMR peaks typical of the dimethylene spacer of cysteamine (Fig. 1, left) and a significant restructuring of the carbonyl region in the IR spectrum (Fig. 1, right). Both NMR and Ellmann's test provided a value of 0.16 for the molar fraction of thiol-bearing dimeric repeating units.

The presence of this relatively small amount of thiol groups did not significantly affect the favorable toxicity profile of HA. We have studied the viability of L929 fibroblasts through the MTS assay, normalizing the data by the protein content of the cell culture; the results are therefore related to the metabolic activity per cell. The two polymers exhibited a stimulatory effect on cellular metabolism; this significant increase in cell viability with increasing HA or HA-SH concentration (Fig. 2) was more noticeable for the $64 \mathrm{kDa}$ polymers.

\subsection{Properties of the photopolymerized networks}

The three gel types were produced through photopolymerization a) of PEGDA in the presence of native HA (type I gels); b) of HA-SH and PEGDA after a short incubation at neutral $\mathrm{pH}$, i.e. using $\mathrm{HA}-\mathrm{SH}$ as a multifunctional chain transfer agent in PEGDA polymerization 


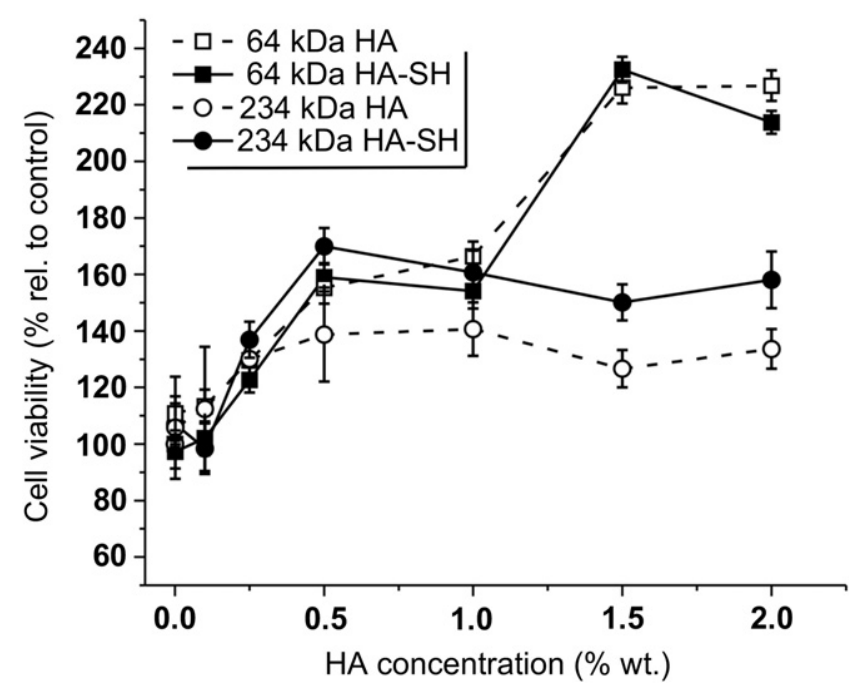

Fig. 2. Cytotoxicity of HA and of HA-SH on L929 murine fibroblasts. The viability of the cells was measured with the MTS metabolic assay after an exposure of $24 \mathrm{~h}$ to different concentrations of the polymers in full medium, normalized for the protein content (measured through the BCA assay) and expressed in reference to the value of cells grown on TCPS under identical conditions without the presence of HA or HA-SH.

(type II gels); c) of HA-SH and PEGDA after a longer incubation at $\mathrm{pH}=8$, which allows for the in situ preparation of an HA-based macromonomer through Michael-type addition of thiols onto acrylates (type III gels).

\subsubsection{Hardening rate}

Storage $\left(G^{\prime}\right)$ and loss $\left(G^{\prime \prime}\right)$ shear moduli were continuously monitored during photopolymerization (see Supplementary data, Fig. 3Sd). The derivative of $G^{\prime}$ vs. time in the proximity of the gel point $\left(\mathrm{d} G /\left.\mathrm{d} t\right|_{\text {gel }}\right)$ provides an indication of the hardening kinetics of the gels, which could be assumed roughly related to the propagation rate in acrylate polymerization. From the results (Fig. 3) the following could be noted:

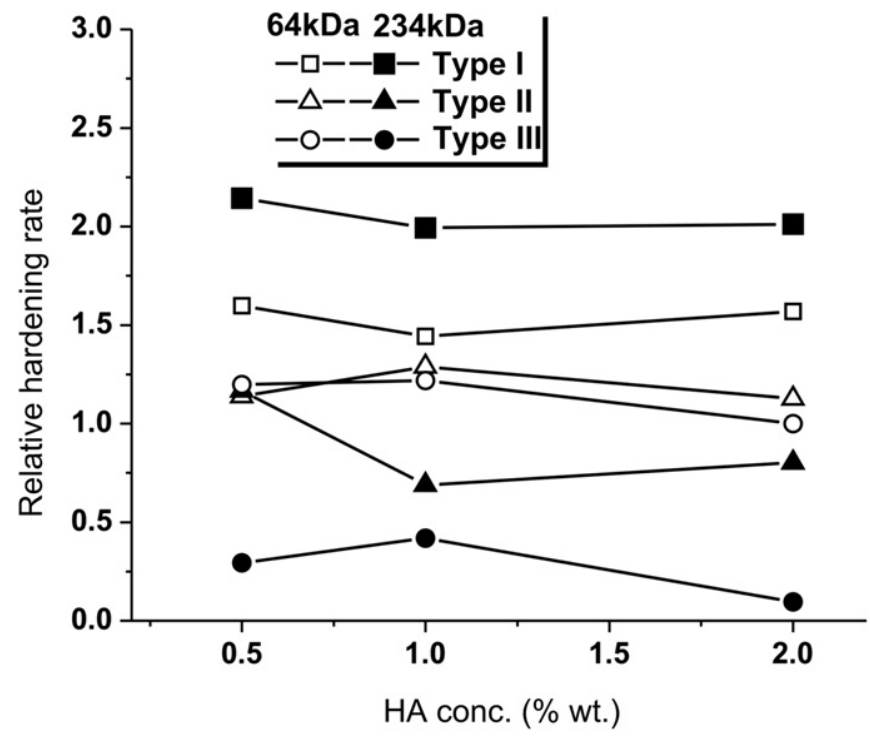

Fig. 3. Relative hardening rates as a function of the type of gels and of HA molecular weight and content. The rates were calculated as the ratios between $\mathrm{d} G^{\prime} /\left.\mathrm{d} t\right|_{\text {gel }}$ values of the HA formulations and that of the control (PEGDA 5 wt.\% with no HA). $G^{\prime}$ was differentiated numerically utilizing a $G^{\prime}$ vs. time curve obtained averaging three experimental curves. We estimate an error of $\pm 20 \%$.
Type I gels (semi-IPNs) showed a more rapid hardening than the PEGDA control, in particular for $234 \mathrm{kDa}$ HA. A separation between HA-rich and PEG-rich domains during polymerization is likely and should occur more promptly with larger HA molecular weight; the corresponding increase of local acrylate concentration in the PEG domains is the likely reason of the increase in propagation rate. No clear dependence on the amount of HA could be recorded, although this may be due to the poor precision of the data.

The hardening kinetics of type II and type III gels was similar to that of the PEGDA control for $64 \mathrm{kDa} \mathrm{HA}$, while it was significantly slowed down for the larger $234 \mathrm{kDa} H A$, above all for type III gels. Comparable (or decreased) hardening rates suggest a comparable acrylate concentration, and therefore a lesser heterogeneity of type II and type III gels in comparison to type I ones. The decreased rate for the $234 \mathrm{kDa}$ (as a chain transfer agent in type II, macromonomer in type III) is probably linked to the larger steric hindrance and thus lower reactivity of the propagating chains containing it.

\subsubsection{Mechanical properties and swelling}

The mechanical behavior of the gels was probed through shear rheology and the results ( $G^{\prime}$ and $\tan \delta$ ) are reported in Fig. 4. It is worth noting that these data were recorded prior to swelling; they therefore depend on the cross-link density, but not on the different hydrophilicity of the produced materials. The gels were then swollen in PBS and their equilibrium swelling values are reported in Fig. 5. These values were similar, although slightly lower, to those recorded in deionized water (see Supplementary data, Fig. 5Sd).

The three variables tested, i.e. the type of gels, the molecular weight of HA and its amount, all affected the mechanical and swelling behavior of the gels. We will now separately examine the role of HA and that of the network architecture:

3.2.2.1. MW and content of $H A$. The gels were significantly softer and less elastic (lower $G^{\prime}$ and higher $\tan \delta$ ) and swelled considerably more with increasing molecular weight and content of HA. For type I gels, this likely derives from the presence of a larger volume fraction of non cross-linked native HA domains. In type II and type III gels this is the consequence of the introduction of HA in the network, which features a molecular weight between cross-links considerably larger than PEGDA: the average molecular weight between thiols is in the range of a few thousands $\mathrm{g} / \mathrm{mol}$.

3.2.2.2. Architecture of the network. Rheology and swelling show a decreasing network density in the order type I > type II $>$ type III gels (Fig. 6): at any given HA molecular weight and concentration, type I gels showed the highest hardness $\left(G^{\prime}\right)$ and elastic character $(\tan \delta)$ and the lowest equilibrium swelling $\left(W_{\infty} / W_{0}\right)$, and the reverse applied to type III gels. We will examine separately semiIPNs (type I) and then covalently bound gels (type II and type III).

Type I gels. Their higher modulus and lower selling degree agree with the picture of a phase-separated material: if phase separation occurs during polymerization, the macroscopic behavior of the material will be determined by the PEG-rich domains, which are surely more densely cross-linked than in type II and type III gels.

Type III gels. The average molecular weight between cross-links, i.e. the distance between neighboring polymerizable groups, is considerably larger in the in situ formed HA macromonomer than in PEGDA, therefore its integration in the network should lead to a pronounced softening/swelling. This is indeed recorded, therefore confirming the type III gels compared to the PEGDA control is therefore an indication of the good integration of the macromonomers in the PEG network.

Type II gels. In type II gels, HA-SH was used as chain transfer agent; thiyl radicals are rapidly generated in the early stages of the photopolymerization and they can either initiate a polyacrylic 

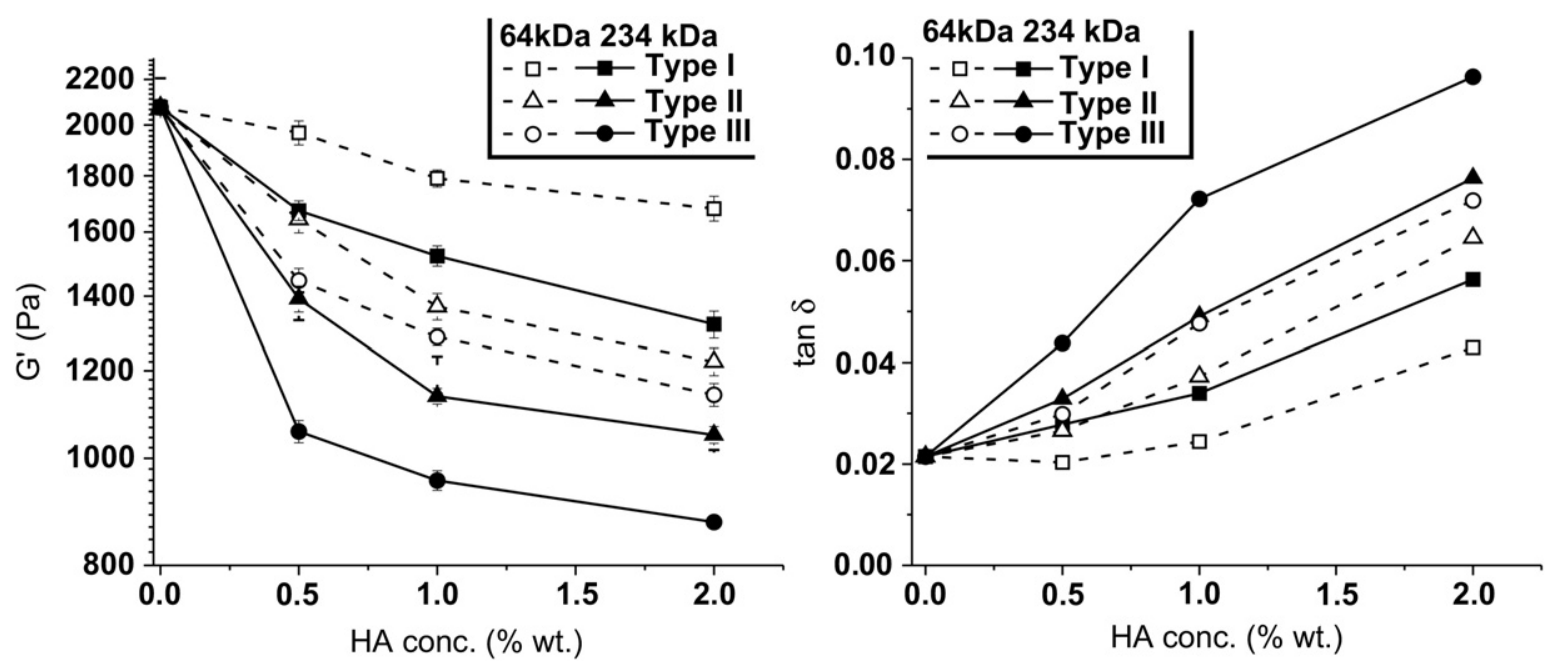

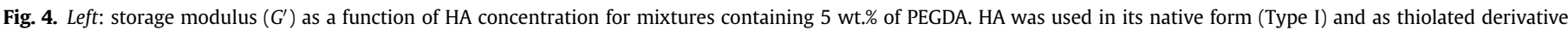

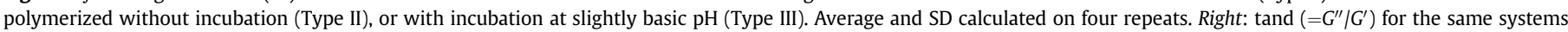
shown in the left panel. SDs omitted for clarity.

chain, or recombine in the form of intra- or intermolecular disulfides. In particular in the second case, disulfides can give rise to elastically active cross-links (Scheme 3 ). By incubation in TCEPcontaining PBS (Fig. 5, right), type II gels showed a consistently higher swelling than in normal PBS, indicating the presence of elastically active cross-links based on disulfides. It is worth pointing out that the presence of disulfides in HA-SH prior to polymerization is negligible (see Experimental Part). We therefore ascribe the intermediate behavior of type II gels to the presence of disulfidebased cross-links, which also implicate the presence of a (possibly continuous) cross-linked HA phase.

\subsubsection{Enzymatic degradability}

The degradability of the gels was assessed by monitoring their swelling degree in response to the presence of hyaluronidase; during the experiments, the medium was exchanged every day to maximize the concentration of active enzyme.

Briefly, we expect the gels to swell if HA is integrated in the network: its degradation would lead to a decrease in the number of elastically active cross-links. On the other hand, a shrinkage is expected upon degradation of a heterogeneous material formed by an HA-rich phase inter-dispersed in a densely cross-linked nondegradable PEG phase: depolymerization and diffusion out of the gel of degraded fragments would reduce the internal osmotic pressure of the material, hence macroscopic shrinkage.

The reaction to the presence of hyaluronidase was followed for up to 7 days (Figs. 7 and 8), showing clear differences between the three gel types (see also Supplementary data, Fig. 6Sd, 7Sd and 8Sd for more detailed data); more specifically:

Type I gels exhibited a very limited weight loss, even after 7 days incubation (Fig. 8, right). The negligible effect of hyaluronidase indicated that HA was not accessible to the enzyme; this result fits the picture of phase separated HA-rich domains, dispersed in a densely cross-linked PEG phase that does not allow the diffusion of the enzyme due to its small mesh size. It is noteworthy that the enzymatic degradability of similar semi-IPNs [17] is to ascribe to their higher content of HA.

Type II gels showed a clear weight loss, which reached a plateau within two days (Fig. 6); at any time (Fig. 7) this effect was more marked with increasing content and MW of HA, indicating that it was
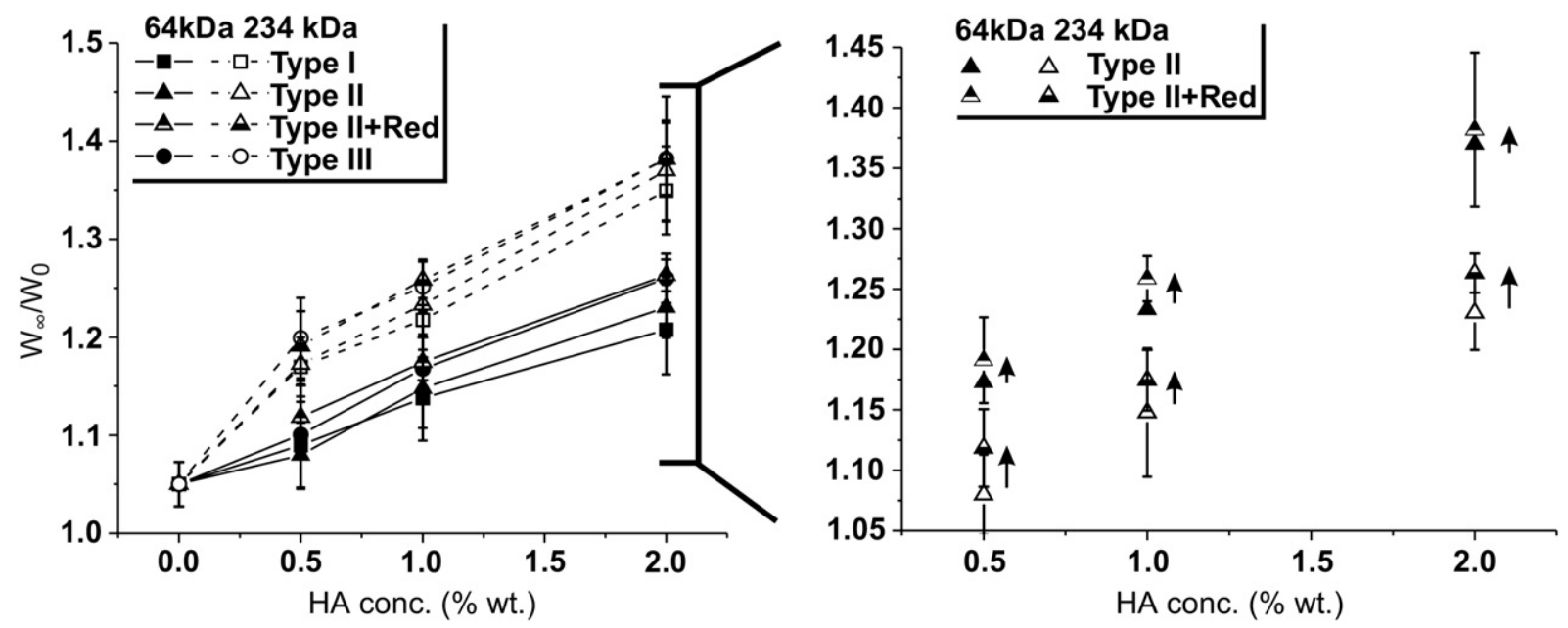

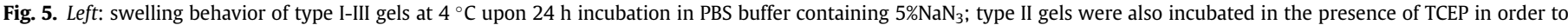

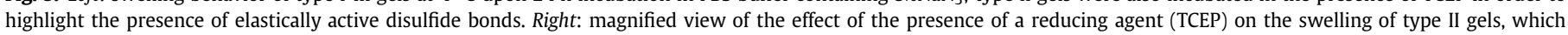
demonstrates the presence of elastically active disulfides. 


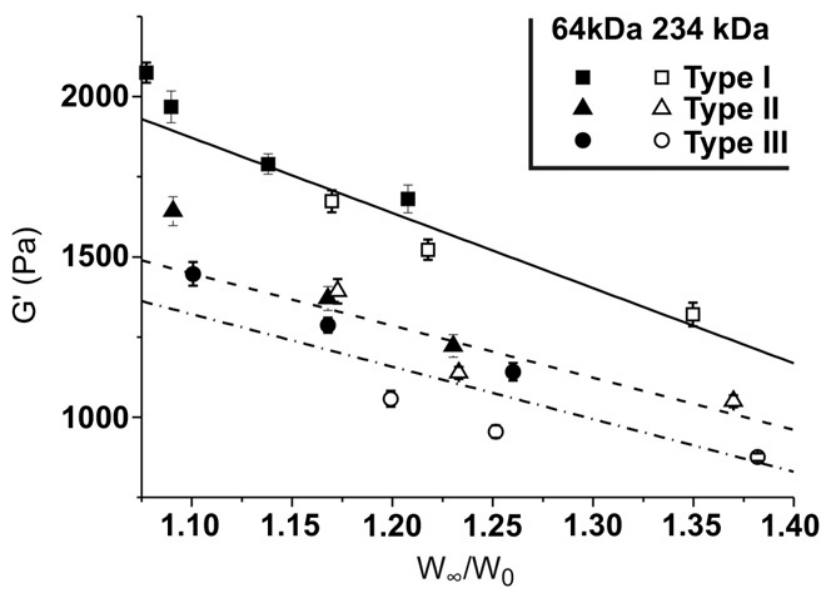

Fig. 6. Plots of $G^{\prime}$ vs. swelling ratio for all the gels investigated in this study; $G^{\prime}$ values refer to the gels after preparation prior to any swelling. Type I gels showed a clearly distinct behavior (use solid line as a reference), which suggests a more rigid character of the network. Type II and type III gels showed a certain overlap (use dotted and dashed lines as references), which can be ascribed to the higher compatibility between HA and PEG achieved in these systems; however, a difference between them is visible too. The lines represent linear fittings of the data points of each class of gels.

related to the action of the enzyme on HA. Two observations: first, the network architecture allowed hyaluronidase to diffuse through the gel; second, the weight loss would suggest HA to be partially phaseseparated from the most densely cross-linked material (vide supra: a homogeneous material would swell). Hyaluronidase may diffuse through these less cross-linked HA-rich domains; HA degradation would then shrink the gel due to decrease of internal osmotic pressure.

Also for type III gels the material performance both in weight gain or loss was proportional to the amount and molecular weight of HA, ensuring its easy accessibility; the time behavior was, however, more complex but at the same time rather typical of bulkdegradable materials, with an initial swelling due to a decreased cross-link density of the network, followed by weight loss due to increasing solubilization of the material. This result is coherent with the picture of an HA integrated with PEG in a mixed network, and accessible due to the rather large low density of cross-links.

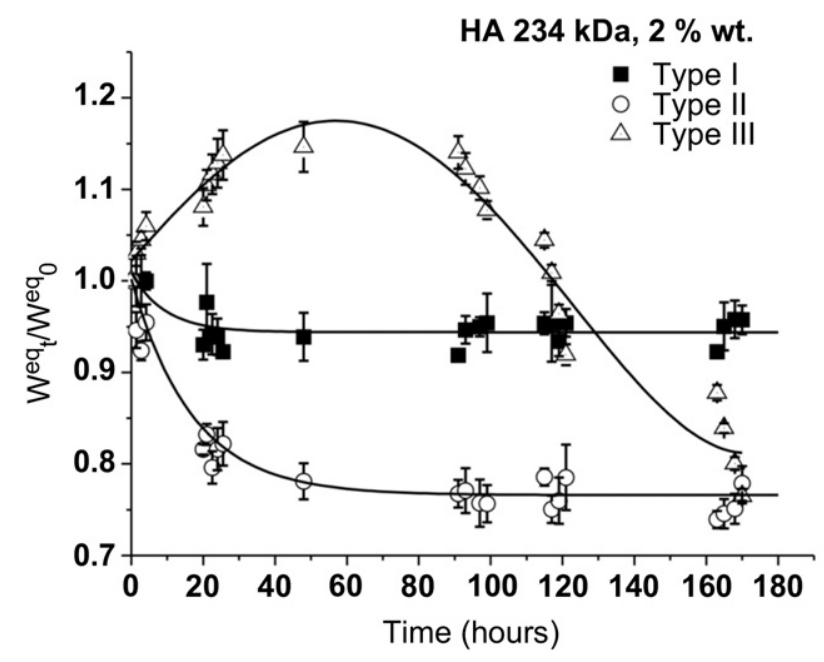

Fig. 7. Equilibrium swelling ratios of the three different hydrogel types based on $2 \mathrm{wt} . \%$ HA 234 kDa during a period of seven days of incubation at $37{ }^{\circ} \mathrm{C}$ buffer containing $200 \mathrm{U} / \mathrm{mL}$ ovine testis hyaluronidase and $0.5 \% \mathrm{NaN}_{3}$; the medium was changed every day in order to allow for the continuous presence of active hyaluronidase. The lines are just guides for eyes.

\subsection{Further investigations on type II gels}

Type II gels exhibited appropriate mechanical properties: whilst $G^{\prime}$ is tunable with HA content and molecular weight, it also always exceeds $1 \mathrm{kPa}$, which is often the minimum to obtain sufficient mechanical stimulation for successful cell growth [43]; additionally $\tan \delta$ generally $<0.06$ ensures a predominantly elastic (="real gel" behavior). These gels also show sensitivity to hyaluronidase; their partial enzymatic degradability is interesting, since it could allow cell-mediated degradation and cell infiltration without a substantial modification of the material properties. Finally, their swelling behavior is not substantially different from that exhibited by the other gel types. Therefore type II gels have been selected for a further study aiming to link the spreading behavior of cells to the (surface) mechanical properties of the gels.

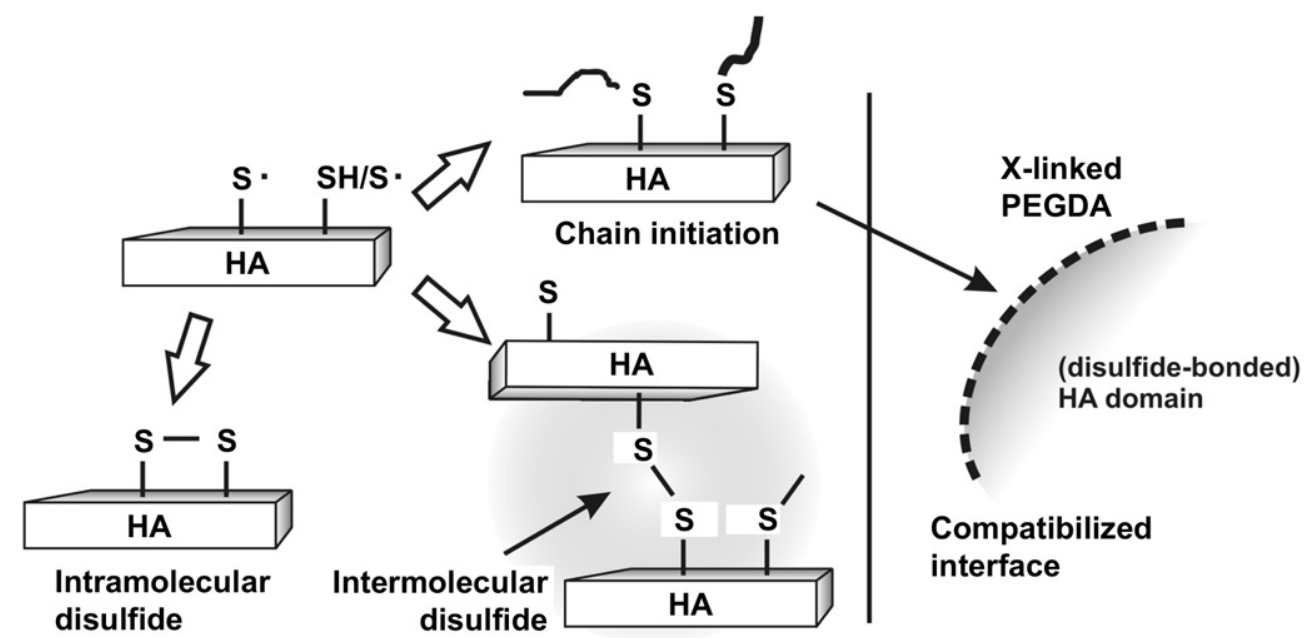

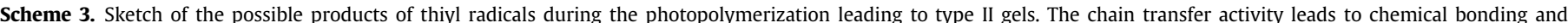

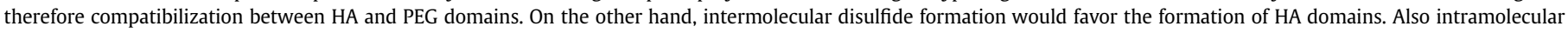
disulfides may have a role in gel swelling, reducing the possibility of expansion of the HA coils. 

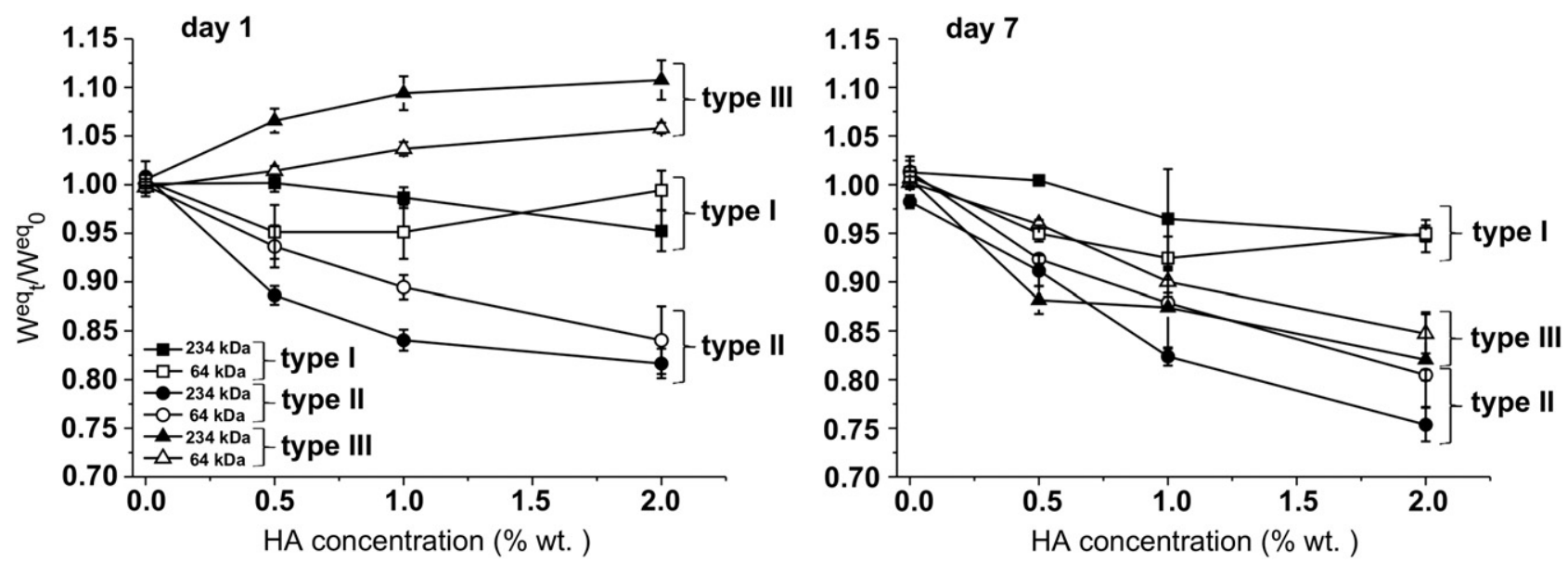

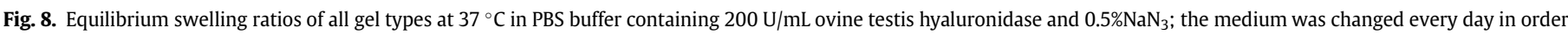
to allow for the continuous presence of active hyaluronidase. Left: 1 day of incubation. Right: 7 days of incubation.

The modulus of HA gels has been known to affect the differentiation of progenitor cells, e.g. differentially promoting neuronal or glial differentiation [44], or modulating chondrogenesis [45]. Typically, cells exert less tension on softer material, and therefore will spread more than on a stiffer material; a thorough example of this relationship has been provided by the group of Burdick who have clearly linked stem cell spreading and circularity to the modulus of densely cross-linked photopolymerized HA gels [43]. Fibroblasts are probably the most popular cell line for spreading and proliferation studies: they are well known to be able to probe the elasticity of a material and accordingly respond to it via cytoskeletal re-organization [46], and clear links between modulus and spreading have been shown on a variety of (2D) matrix constructs [40,47].

Adhesion complexes, e.g. integrin/RGD peptides, can link the cytoskeletal components to the extracellular matrix, therefore cell spreading on an integrin-binding substrate can be seen as a reporter of the matrix stiffness, generating intracellular contractile forces, mediated by cross-linking of actin and myosin chains which in turn are transmitted to the substrate as traction forces [48-50]. In our study, we have therefore studied the adhesion of L929 fibroblasts to HA hydrogels using an integrin-mediated anchoring to RGD peptides, employing a constant density of RGD residues on gels (1:20 RGD per acrylate) for type II gels with variable mechanical properties and HA content/molecular weight.

\subsubsection{Surface properties through nanoindentation}

Initially, nanoindentation of equilibrium-swollen gels was attempted, but technical problems were encountered with unequivocally identifying the tip/gel surface contact point (zero indentation). As a consequence all nanoindentation analyses was performed on type II gels placed in a humidified environment after polymerization.

Examples of nanoindentation curves are presented in Fig. 9. Young's modulus $(E)$ values were calculated from the nanoindentation curves using a Hertzian model (Fig. 10, left) and confirmed the trends seen through swelling measurements and shear rheology; the good agreement between $E$ and $G^{\prime}$ values (Fig. 10, left) indicated increasingly softer materials with increasing HA content and molecular weight. Force maps (Fig. 11) showed that in each sample the Young's modulus values generally varied within $\pm 10 \%$ in $10 \times 10 \mu \mathrm{m}$ areas, ensuring that cells deposited on the gel surfaces would experience mechanically homogeneous materials.
It is noteworthy that the relationship between $E$ and $G^{\prime}$ is not constant. In isotropic hydrogels, Poisson's ratio can be generally assumed to be in the range $0.45-0.5$ [51]; since in the range $0.1-10 \mathrm{~Hz} \mathrm{G}^{\prime}$ was largely independent on frequency, and $\tan \delta$ was always $<0.1$ thus $G^{\prime} \sim G$, the relationship between the two moduli could therefore be approximated to $E=2 G(1+\nu) \approx 3 G$. However an $E / G^{\prime}$ ratio close to 3 could be observed only for the gels containing $234 \mathrm{kDa} \mathrm{HA}$, i.e. those with the lowest cross-linking density, whereas $64 \mathrm{kDa}$ HA gels provided a ratio of about 8 and the control PEGDA of about 13.5 (Fig. 10, right). The dependency of the $E / G^{\prime}$ ratio on HA molecular weight can hardly be ascribed to a major difference in the network structure; rheological and degradability results indicated a qualitative similarity within type II networks. Since $G^{\prime}$ and $E$ are obtained through, respectively, bulk and surface measurements, this effect may be due to the formation of a more densely cross-linked "skin" on the gel surface during photopolymerization; however, although much care was devoted to avoid drying of the materials, we cannot completely exclude a higher propensity of drying for gels without HA or with $64 \mathrm{kDa} H A$.

\subsubsection{Cell spreading and proliferation}

Fibroblasts are adherent cells and their survival depends upon anchorage onto a solid surface; prolonged detachment and suspension in a fluid can trigger apoptotic phenomena, which are typically referred to as "anoikis" [52]. On hydrophobic substrates such as tissue culture polystyrene (TCPS), cell attachment is

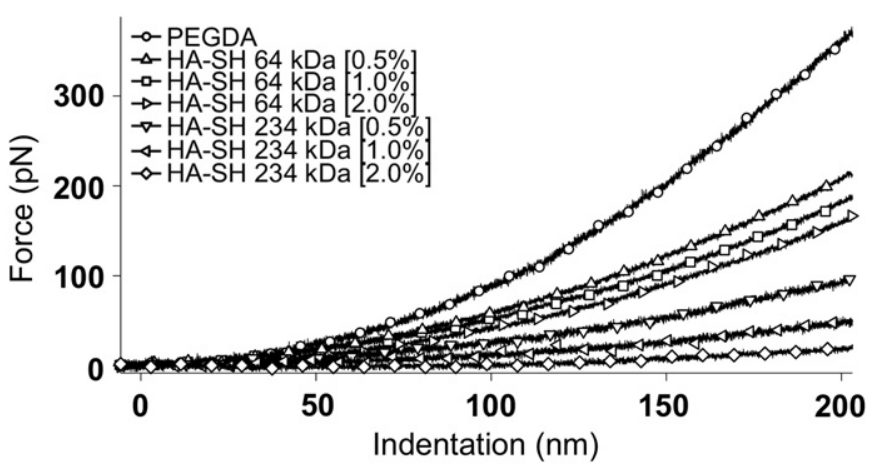

Fig. 9. Examples of nanoindentation curves. The experiments were performed using a cantilever of elastic constant $0.14 \mathrm{~N} / \mathrm{m}$ on "as prepared" type II gels in humid air to avoid dehydration during the experiment. 

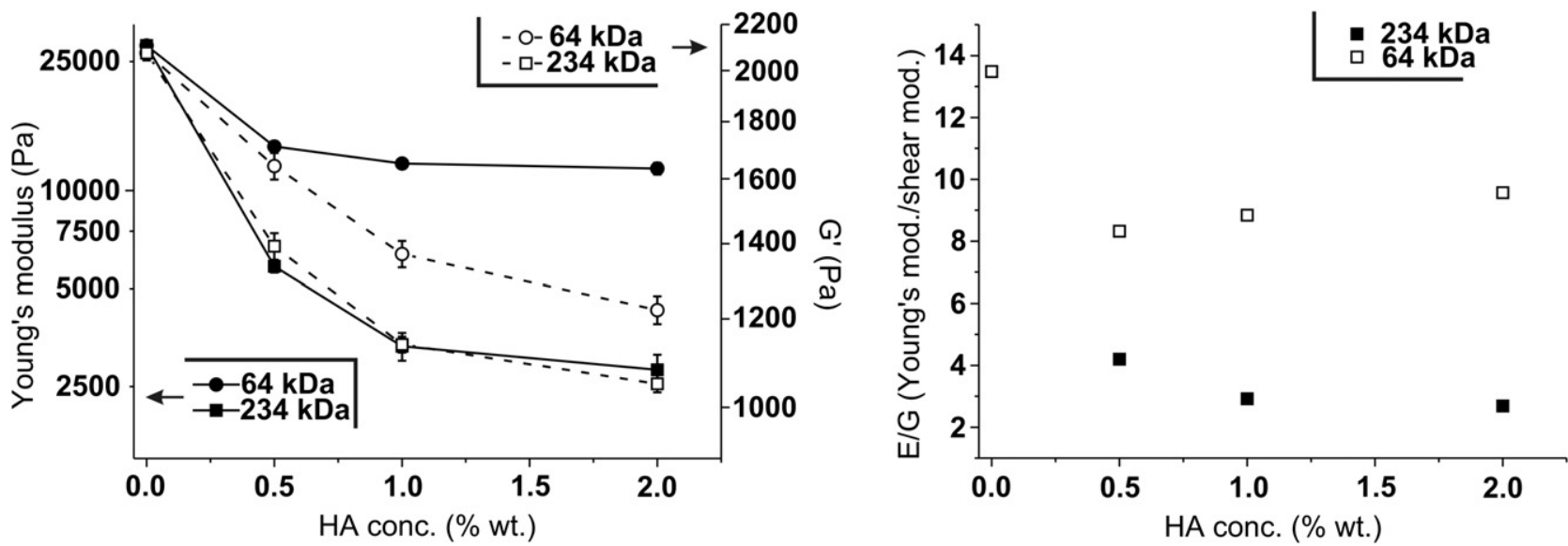

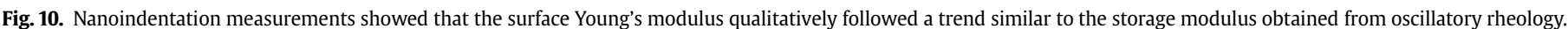

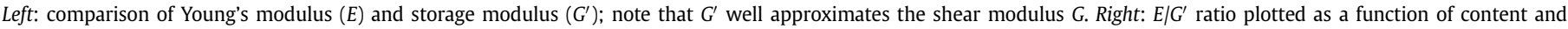
molecular weight of HA. Since $G^{\prime} \sim G$, this ratio should be constant in ideal, isotropic hydrogels.

typically mediated through adsorbed matrix proteins, while on hydrophilic, non-ionic and non-protein adsorbing substrates, such as PEG [53] and also on HA, the negligible protein adsorption coupled with the lack of strong polar adhesion forces frustrate cell adhesion. In our study, preliminary experiments have confirmed the complete absence of adherent cells on non-functional type II gels after one, two or three days of culture. The use of covalently attached cell adhesion peptides to allow adhesion and

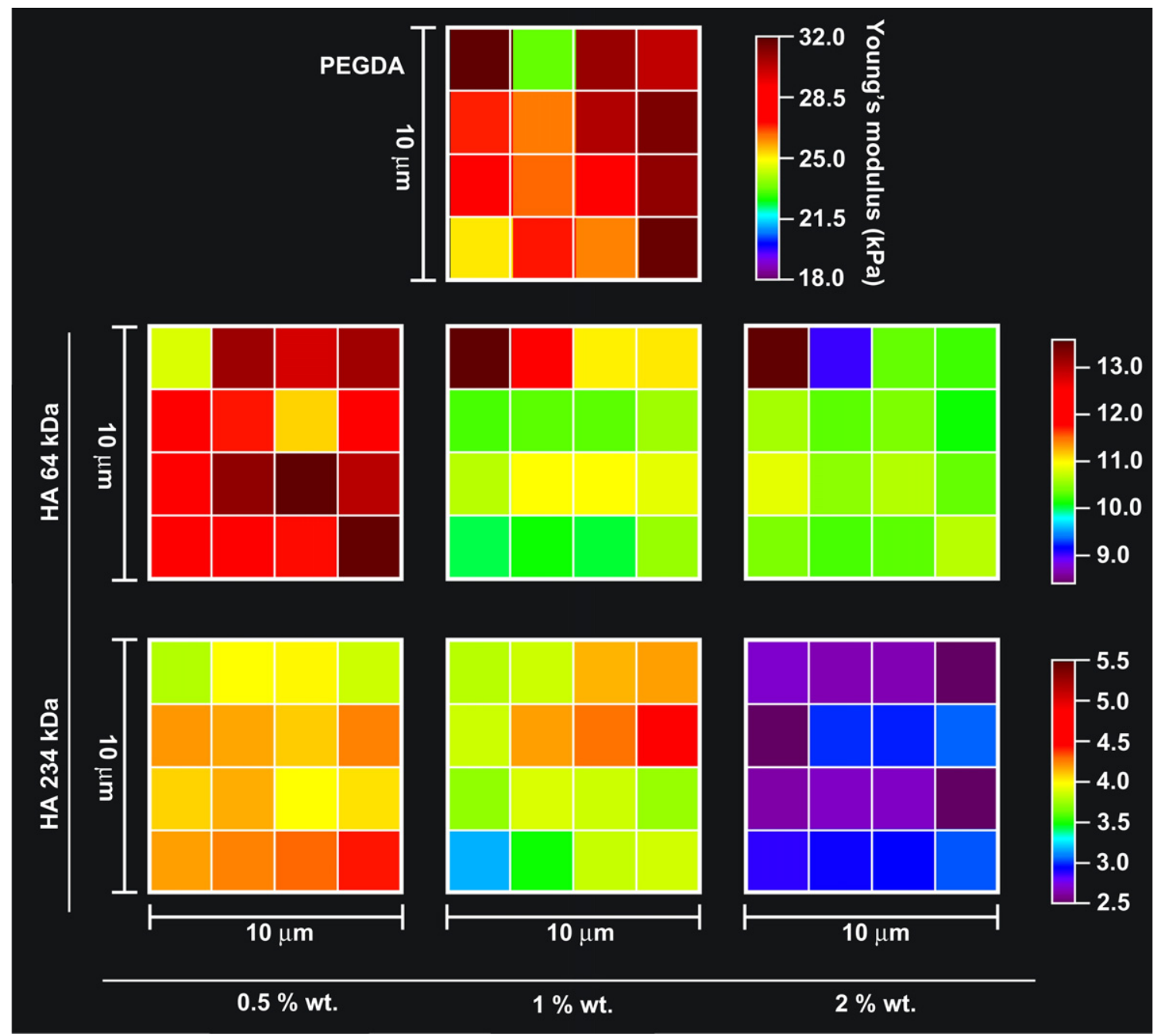

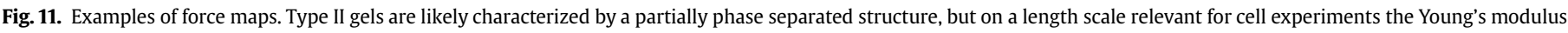
was reasonably homogeneous: the modulus of PEGDA control varied within $24-30 \mathrm{kPa}$, and type II gels showed even lower relative variations. 

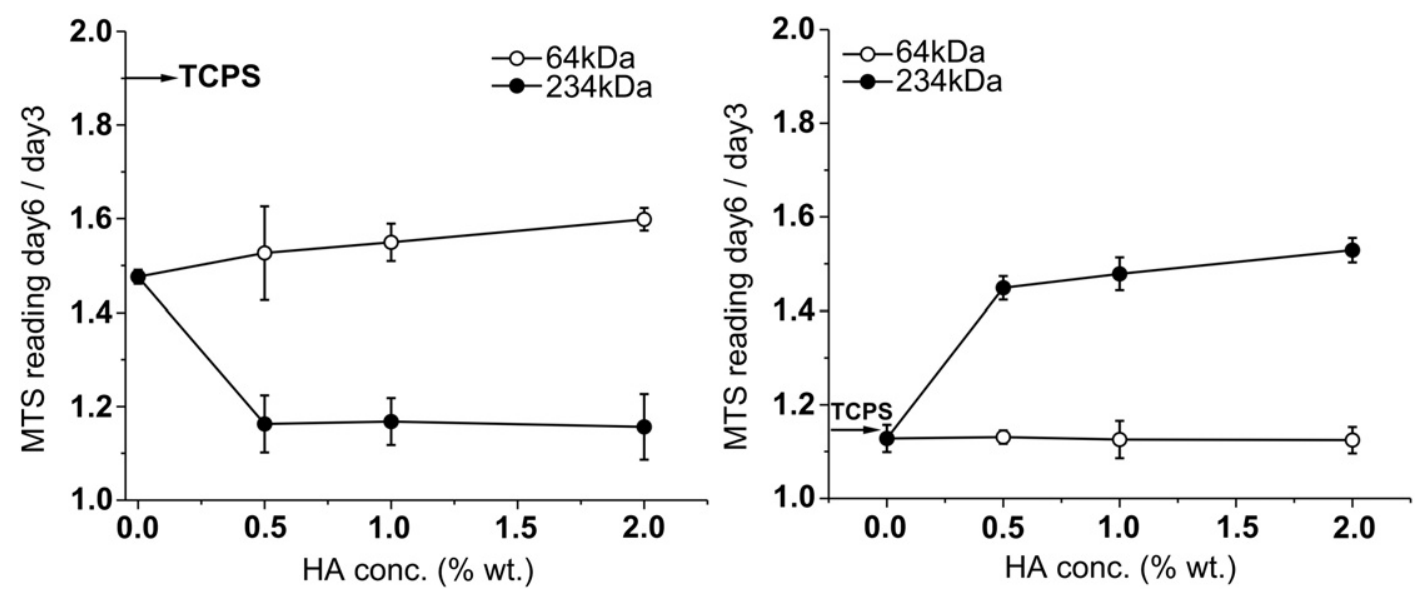

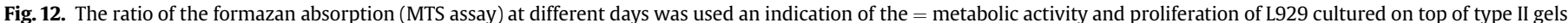

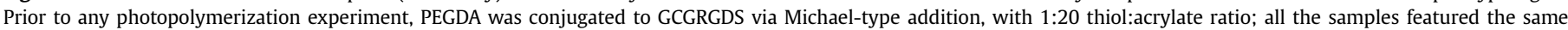

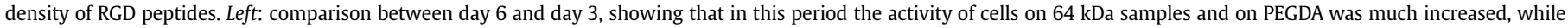
cells on $234 \mathrm{kDa}$ samples did not show significant increases. Right: the opposite was observed in the day 9/day 6 comparison.
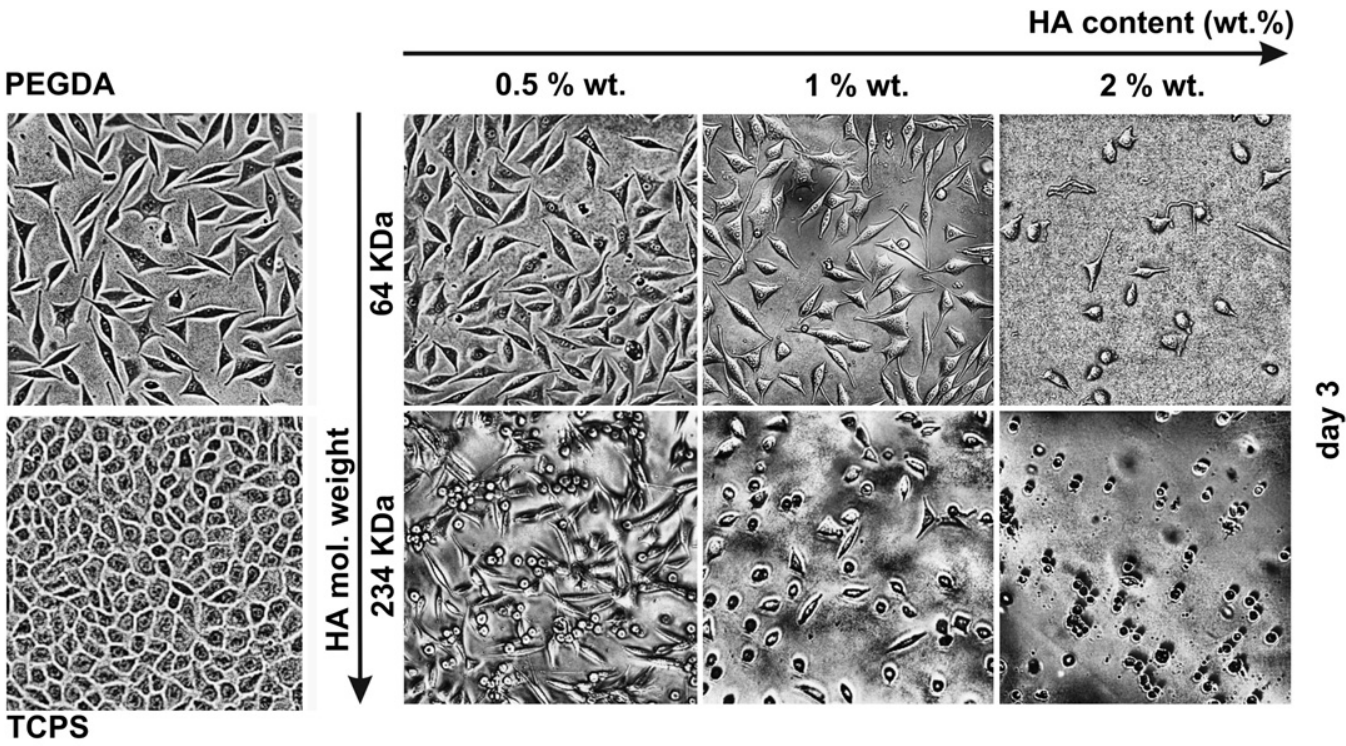

PEGDA
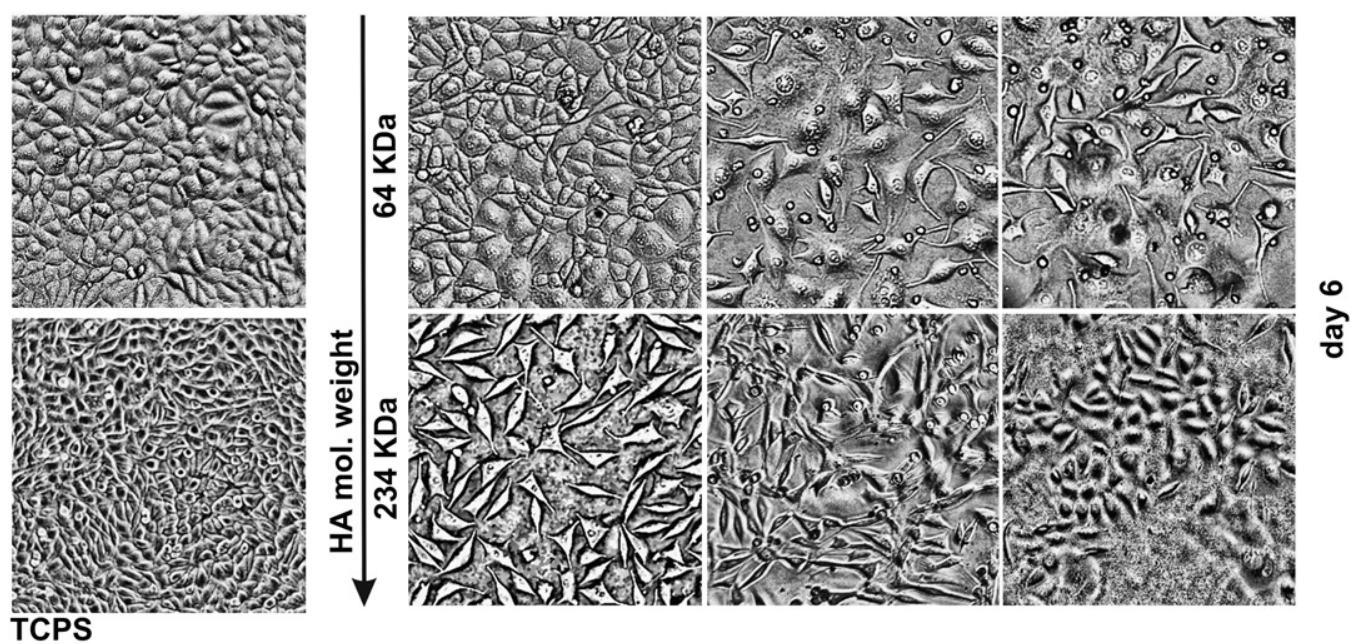

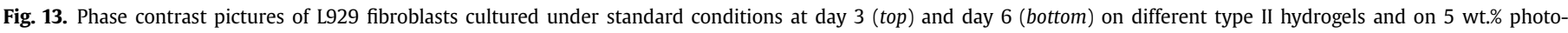
polymerized PEGDA and on TCPS as controls. The density of RGD peptide was kept constant for all hydrogels (1:20 thiol/acrylate molar ratio). 
A
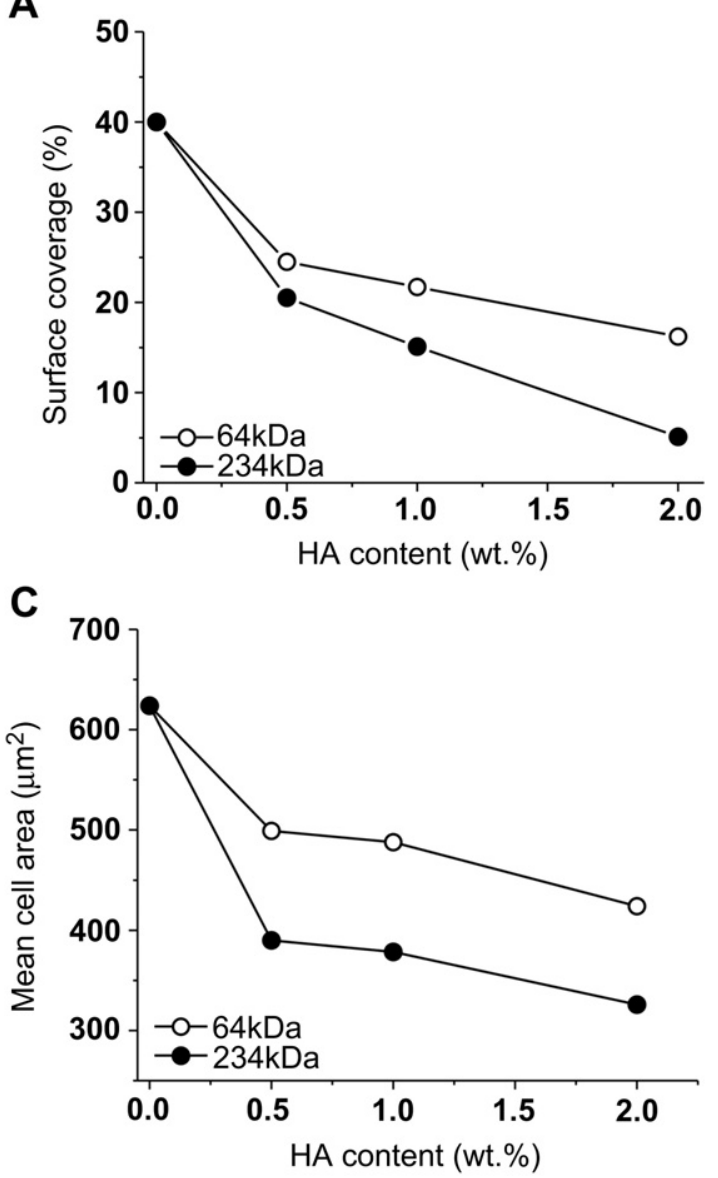

B

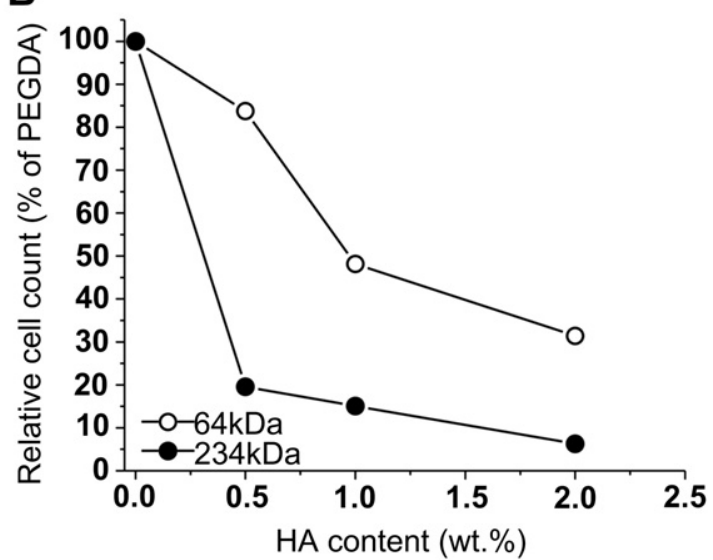

D

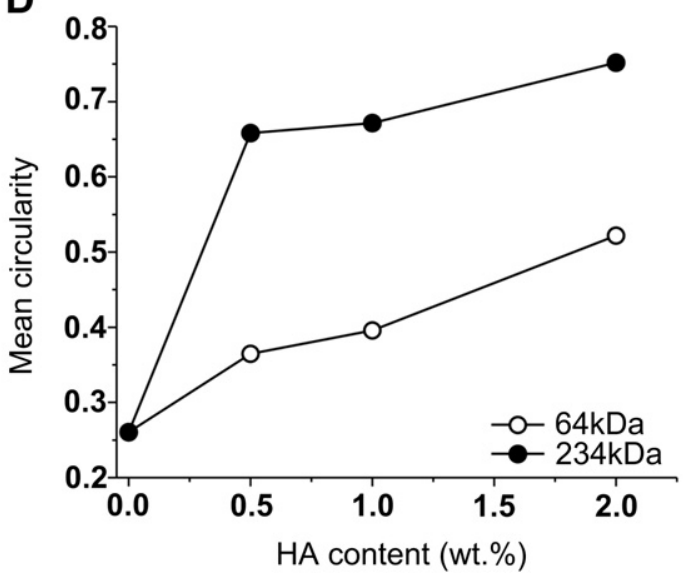

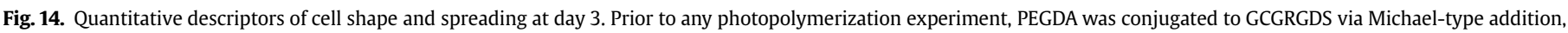

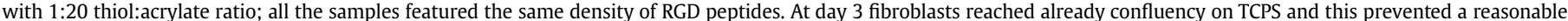

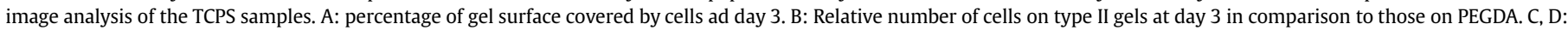

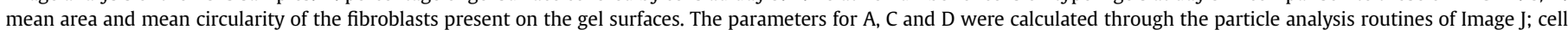

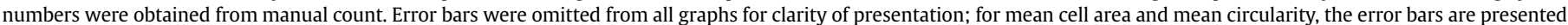
in Fig. 15.

colonization of protein-repellent hydrophilic materials by adherent cells was originally pioneered by Hubbell [54-58] and has now become a widespread standard technique. Following this approach, we have employed an RGDS- ( $\rightarrow$ binding to the most ubiquitous integrins, the $\alpha_{v} \beta_{3}$ and $\alpha_{5} \beta_{1}$ dimers) and cysteincontaining peptide; the peptide was pre-incubated with PEGDA to allow the Michael-type addition of the cystein thiol onto acrylate groups, and thus its covalent incorporation in the photopolymerized network. Murine L929 fibroblasts were then seeded on top of the gels and cultured in full DMEM under standard conditions for cell culture $\left(37{ }^{\circ} \mathrm{C}, 5 \% \mathrm{CO}_{2}\right)$ for up to 9 days, replacing the medium on day 3,6 , and 9 . All gels presented the same density of RGD residues, allowing to ascribe any difference in cell spreading/proliferation to differences in HA content/ molecular weight, or in the resulting mechanical properties.

We have performed MTS tests at day 3, 6 and 9; these measurements offer a combined information about cell number and metabolic activity, providing a general overview about the fibroblast proliferative activity. The results highlighted a rather sharp difference between 64 and $234 \mathrm{kDa}$ HA-containing gels (Fig. 12): in the day 3 - day 6 period the overall metabolic activity increased in the order TCPS $>64$ kDA or control PEGDA gels $>234$ kDa HA gels (Fig. 12, left).

The opposite behavior was recorded for the day 6 - day 9 period (Fig. 12, right); in this second phase the slow proliferative activity of TCPS, PEGDA, HA $64 \mathrm{kDa}$ stemmed from an already reached confluency, while the sound increase for the $234 \mathrm{kDa}$ HA gels may derive from a modification of the gel surface, e.g. because of deposition of a cell-produced matrix, or of significant degradation of HA. In order to provide a semi-quantitative relationship between cell behavior and the properties of the gels before remodeling, we have therefore focused on day 3 and day 6 data.

3.3.2.1. Cell morphology. At day 3 fibroblasts reached confluency on TCPS, while they were present in lower numbers on the gels. On the PEGDA control, cells showed a spindle shape phenotype, while on HA-containing gels they exhibited an increasing fraction of rounder phenotype with increasing HA concentration and molecular weight (Fig. 13, top). At day 6 a majority of spindle-shaped cells could be seen on all gels, although the cell density was yet markedly lower on high HA content gels (Fig. 13, bottom).

As in a previous study [53], we have further characterized the differential spreading of fibroblasts on the gels at day 3 using numerical parameters such as the surface coverage and the density, average area and average circularity of individual cells (Fig. 14). This analysis could not provide meaningful results at day 6 , since the confluent or semi-confluent state of most samples did not allow the automatic individuation of single cells.

3.3.2.2. Surface coverage and cell number. The cells cultured on control (RGD-containing) PEGDA gels (Fig. 14, A and B) showed the 

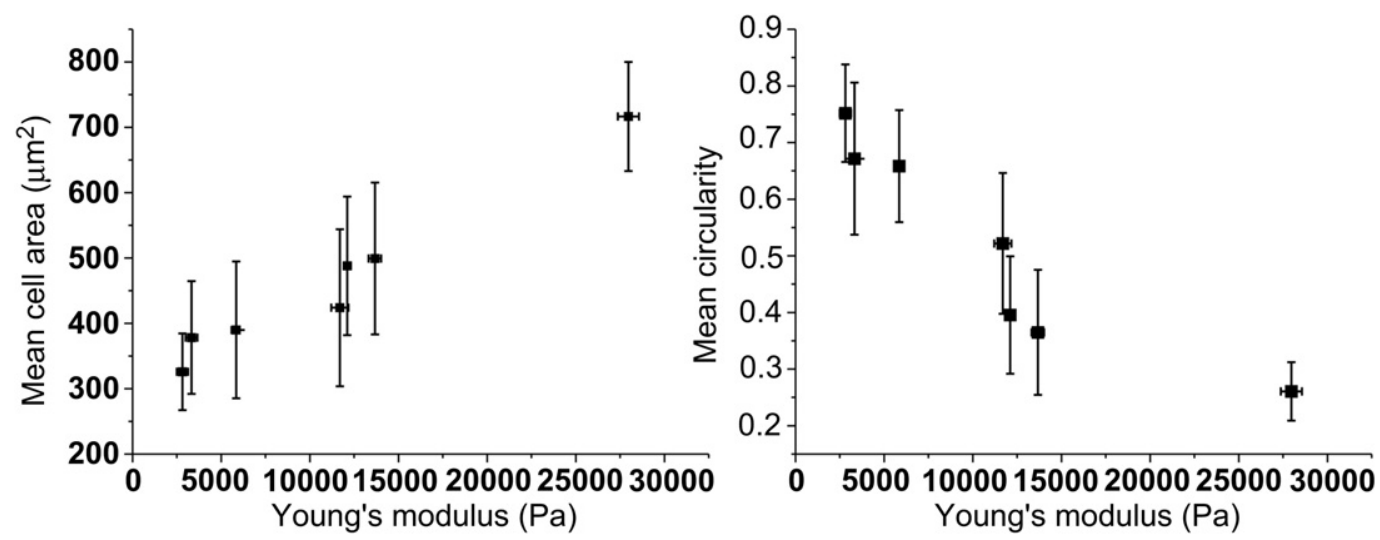

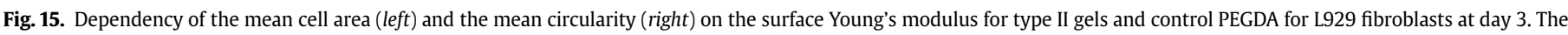

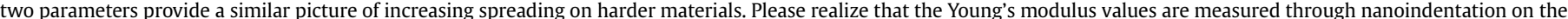

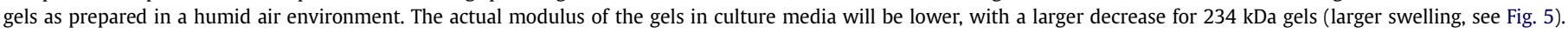

highest degree of surface coverage, which then decreased with both increasing content and molecular weight of HA. Monitoring the cell numbers in relation to the control, it was apparent that the presence of HA reduced dramatically the number of adherent cells, specifically for the larger $234 \mathrm{kDa} \mathrm{HA}$.

Average cell area and circularity (Fig. 14, C and D): cells cultured on control PEGDA gels showed the lowest values of circularity $(\sim 0.26)$ and the largest average area $\left(550-750 \mu \mathrm{m}^{2}\right)$, which corresponded to a majority of spindle and tripod phenotypes, typical of fibroblasts spreading flat on adhesive substrates such as TCPS. The circularity then increased and the average area decreased with both molecular weight and content of HA. On $2 \% 234$ kDa HA gels, fibroblasts showed a predominantly circular section with an area of 300-400 $\mu \mathrm{m}^{2}$.

Keeping in mind that all gels had the same density of RGD peptides, the above indicators showed a clear relationship between cell spreading and the HA content/mechanical properties of the material. We are inclined to interpret this effect as a mostly mechanical one, since networks differing only in the molecular weight of covalently incorporated HA macromolecules can hardly show largely different ligand/receptor interactions.

Therefore plotting circularity and cell area as a function of Young's modulus (Fig. 15), a proportional relation between spreading and gel hardness becomes apparent. These findings are in line with the widespread literature evidence of a positive correlation between cell spreading (fibroblasts, myocytes, stem cells) or slower growth (stem cells) and the modulus of HA-based hydrogels they are seeded on $[59,60]$.

3.3.2.3. Metabolic activity. Cell numbers at day 3 varied greatly between different gels; further, decreasing HA content/molecular weight (=increasing modulus) apparently increased proliferation (Fig. 13; see also Fig. 14B). In order to relate the material properties to effects on individual cells, we have normalized the MTS results showed in Fig. 12 by the cell number. Cells on PEGDA showed negligible differences from TCPS; on the other hand, increasing both content and molecular weight of HA dramatically increased the metabolic activity per cell (Fig. 16, left). For example, at day 3 fibroblasts on $234 \mathrm{kDa}$ HA gels (largely round phenotype) showed an at least 10-fold higher MTS activity/cell than those on TCPS; at day 6, on the same gels they showed a significantly higher fraction of spindle shape cells, but the activity was still at least 5-fold higher than on TCPS.

It is noteworthy that the MTS activity per cell appeared to have an inverse relationship with cell spreading (see also Supplementary data, Fig. 10Sd). Correspondingly, the dependency of the activities per cell both at day 3 and day 6 on the gel Young's modulus (Fig. 16, right) was substantially identical to that of circularity (Fig. 15).

This convergence of a metabolic assay with morphological indicators appears to indicate a trend for L929 fibroblasts of increased
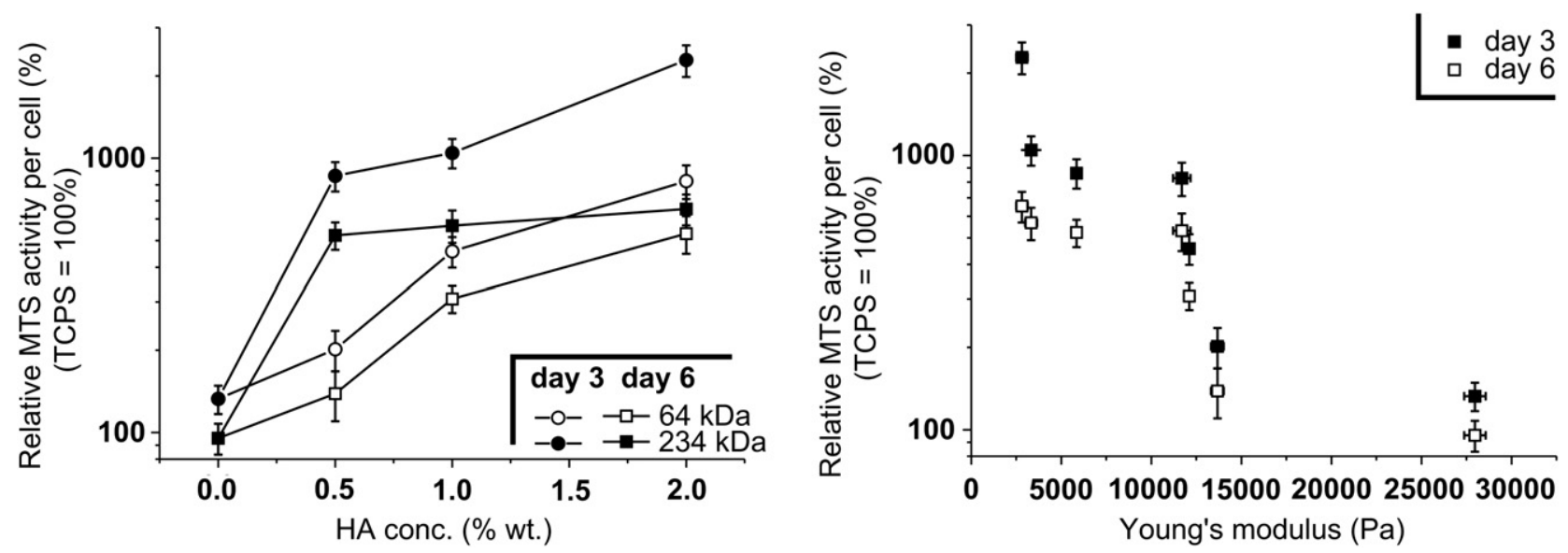

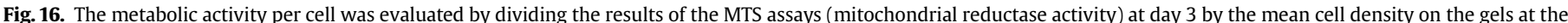

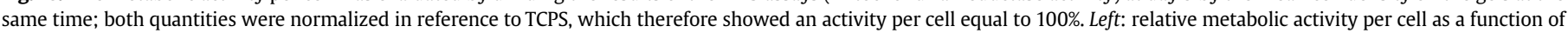
the concentration of HA in the type II gels. Right: relative metabolic activity per cell as a function of the Young's modulus of type II gels. 
spreading but decreased cell activation on substrates with higher Young's modulus. At this point it is difficult to speculate on the nature of this activation, although it may be related to an increased matrix production to allow better cell adhesion and spreading. It is also noteworthy that the MTS assay only explores mitochondrial reductase activity; therefore more tests and on additional cell types should be performed to reliably extend these results to the whole cell metabolism.

In summary, fibroblasts behaved differently on gels differing in the amount and molecular weight of HA; according to literature examples, the presence of HA may not be sufficient to alter cell spreading or proliferation, if the elastically active elements of the matrix are untouched [61]. We therefore ascribe our findings to the mechanical effects of the presence of HA (different cross-linking density and hence different modulus and swelling), rather than to direct interactions of the embedded polysaccharides with cell surface receptors.

\section{Conclusions}

We have demonstrated the possibility to use appropriate reactive processing techniques to fine tune the (bio)physical properties of HA-based gels and the spreading, activation and proliferation rate of cells on their surface. Our study has first focused on the optimization of the network architecture of HA-containing gels. We aimed to select materials 1 ) where HA was a major determinant of the material performance, but a minor component in weight, 2) that preserved sensitivity to hyaluronidase and hence offered the possibility of a cell-mediated remodeling, 3) that presented sufficient mechanical hardness to allow cell spreading. By evaluating semi-IPNs (HA dispersed in a PEGDA network: type I gels), partially phase-separated co-networks (HA-SH as chain transfer agent during PEGDA polymerization: type II gels) and homogeneous conetworks (in situ preparation and polymerization of $\mathrm{HA}-\mathrm{SH} /$ PEGDA macromonomers: type III gels), type II gels emerged as the best candidate. We have then confirmed the quantitative relationship between fibroblast spreading and the composition/ mechanical properties of type II gels: by employing gels with a constant density of adhesion peptides, we have verified the direct link between surface Young's modulus and cell spreading using indicators of cell morphology and metabolism.

\section{Acknowledgments}

SO gratefully acknowledge BBSRC for a studentship. MJS is a Research into Ageing Senior Research Fellow.

\section{Appendix. Supplementary data}

Supplementary data related to this article can be found online at doi:10.1016/j.biomaterials.2011.05.044.

\section{References}

[1] Asari A, Miyauchi S, Miyazaki K, Hamai A, Horie K, Takahashi T, et al. Intracellular and extracellular localization of hyaluronic-acid and proteoglycan constituents (chondroitin sulfate, keratan sulfate, and protein core) in articular-cartilage of rabbit tibia. J Histochem Cytochem 1992;40(11): 1693-703.

[2] Evanko SP, Parks WT, Wight TN. Intracellular hyaluronan in arterial smooth muscle cells: association with microtubules, RHAMM, and the mitotic spindle. J Histochem Cytochem 2004;52(12):1525-35.

[3] Prestwich GD, Kuo J. Chemically-modified HA for therapy and regenerative medicine. Curr Pharm Biotechnol 2008;9(4):242-5.

[4] Ossipov DA. Nanostructured hyaluronic acid-based materials for active delivery to cancer. Expert Opin Drug Deliv 2010;7(6):681-703.
[5] Chung C, Mesa J, Miller GJ, Randolph MA, Gill TJ, Burdick JA. Effects of auricular chondrocyte expansion on neocartilage formation in photocrosslinked hyaluronic acid networks. Tissue Eng 2006;12(9):2665-73.

[6] Masters KS, Shah DN, Leinwand LA, Anseth KS. Crosslinked hyaluronan scaffolds as a biologically active carrier for valvular interstitial cells. Biomaterials 2005;26(15):2517-25.

[7] Cai SS, Liu YC, Shu XZ, Prestwich GD. Injectable glycosaminoglycan hydrogels for controlled release of human basic fibroblast growth factor. Biomaterials 2005;26(30):6054-67.

[8] Kim J, Kim IS, Cho TH, Lee KB, Hwang SJ, Tae G, et al. Bone regeneration using hyaluronic acid-based hydrogel with bone morphogenic protein-2 and human mesenchymal stem cells. Biomaterials 2007;28(10):1830-7.

[9] Vercruysse KP, Marecak DM, Marecek JF, Prestwich GD. Synthesis and in vitro degradation of new polyvalent hydrazide cross-linked hydrogels of hyaluronic acid. Bioconjug Chem 1997;8(5):686-94.

[10] Bulpitt P, Aeschlimann D. New strategy for chemical modification of hyaluronic acid: preparation of functionalized derivatives and their use in the formation of novel biocompatible hydrogels. J Biomed Mater Res 1999;47(2): $152-69$.

[11] Luo Y, Kirker KR, Prestwich GD. Cross-linked hyaluronic acid hydrogel films: new biomaterials for drug delivery. J Control Release 2000;69(1):169-84.

[12] Shu XZ, Liu YC, Palumbo FS, Lu Y, Prestwich GD. In situ crosslinkable hyaluronan hydrogels for tissue engineering. Biomaterials 2004;25(7-8): 1339-48.

[13] Serban MA, Prestwich GD. Synthesis of hyaluronan haloacetates and biology of novel cross-linker-free synthetic extracellular matrix hydrogels. Biomacromolecules 2007;8(9):2821-8.

[14] Shu XZ, Liu YC, Luo Y, Roberts MC, Prestwich GD. Disulfide cross-linked hyaluronan hydrogels. Biomacromolecules 2002;3(6):1304-11.

[15] Leach JB, Bivens KA, Patrick CW, Schmidt CE. Photocrosslinked hyaluronic acid hydrogels: natural, biodegradable tissue engineering scaffolds. Biotechnol Bioeng 2003;82(5):578-89.

[16] Burdick JA, Chung C, Jia XQ, Randolph MA, Langer R. Controlled degradation and mechanical behavior of photopolymerized hyaluronic acid networks. Biomacromolecules 2005;6(1):386-91.

[17] Park YD, Tirelli N, Hubbell JA. Photopolymerized hyaluronic acid-based hydrogels and interpenetrating networks. Biomaterials 2003:24(6):893-900.

[18] Smeds KA, Grinstaff MW. Photocrosslinkable polysaccharides for in situ hydrogel formation. J Biomed Mater Res 2001;54(1):115-21.

[19] Crescenzi V, Cornelio L, Di Meo C, Nardecchia S, Lamanna R. Novel hydrogels via click chemistry: synthesis and potential biomedical applications. Biomacromolecules 2007;8(6):1844-50.

[20] Kurisawa M, Chung JE, Yang YY, Gao SJ, Uyama H. Injectable biodegradable hydrogels composed of hyaluronic acid-tyramine conjugates for drug delivery and tissue engineering. Chem Commun 2005;34:4312-4.

[21] Segura T, Anderson BC, Chung PH, Webber RE, Shull KR, Shea LD. Crosslinked hyaluronic acid hydrogels: a strategy to functionalize and pattern. Biomaterials 2005;26(4):359-71.

[22] Bryant SJ, Anseth KS. Hydrogel properties influence ECM production by chondrocytes photoencapsulated in poly(ethylene glycol) hydrogels. J Biomed Mater Res 2002;59(1):63-72.

[23] Elisseeff J, Anseth K, Sims D, McIntosh W, Randolph M, Langer R. Transdermal photopolymerization for minimally invasive implantation. Proc Natl Acad Sci U. S A 1999;96(6):3104-7.

[24] Elisseeff J, McIntosh W, Anseth K, Riley S, Ragan P, Langer R. Photoencapsulation of chondrocytes in poly(ethylene oxide)-based semi-interpenetrating networks. J Biomed Mater Res 2000;51(2):164-71.

[25] Nguyen KT, West JL. Photopolymerizable hydrogels for tissue engineering applications. Biomaterials 2002 Nov;23(22):4307-14.

[26] Fedorovich NE, Oudshoorn MH, van Geemen D, Hennink WE, Alblas J, Dhert WJA. The effect of photopolymerization on stem cells embedded in hydrogels. Biomaterials 2009;30(3):344-53.

[27] Hwang NS, Varghese S, Lee HJ, Theprungsirikul P, Canver A, Sharma B, et al. Response of zonal chondrocytes to extracellular matrix-hydrogels. FEBS Lett 2007;581(22):4172-8.

[28] Hwang NS, Varghese S, Zhang Z, Elisseeff J. Chondrogenic differentiation of human embryonic stem cell-derived cells in arginine-glycine-aspartate modified hydrogels. Tissue Eng 2006;12(9):2695-706.

[29] Kutty JK, Cho E, Lee JS, Vyavahare NR, Webb K. The effect of hyaluronic acid incorporation on fibroblast spreading and proliferation within PEGdiacrylate based semi-interpenetrating networks. Biomaterials 2007; 28(33):4928-38.

[30] Zajac AL, Discher DE. Cell differentiation through tissue elasticity-coupled, myosin-driven remodeling. Curr Opin Cell Biol 2008;20(6):609-15.

[31] Ehrbar M, Sala A, Lienemann P, Ranga A, Mosiewicz K, Bittermann A, et al. Elucidating the role of matrix stiffness in 3D cell migration and remodeling. Biophysical J 2011 Jan;100(2):284-93.

[32] Saha K, Pollock JF, Schaffer DV, Healy KE. Designing synthetic materials to control stem cell phenotype. Curr Opin Chem Biol 2007;11(4):381-7.

[33] Cramer NB, Reddy SK, O’Brien AK, Bowman CN. Thiol-ene photopolymerization mechanism and rate limiting step changes for various vinyl functional group chemistries. Macromolecules 2003;36(21):7964-9.

[34] Salinas CN, Anseth KS. Mixed mode thiol-acrylate photopolymerizations for the synthesis of PEG-peptide hydrogels. Macromolecules 2008;41(16): 6019-26. 
[35] Ellman GL, Courtney KD, Andres V, Featherstone RM. A new and rapid colorimetric determination of acetylcholinesterase activity. Biochem Pharmacol 1961;7(2):88.

[36] Hutter JL, Bechhoefer J. Calibration of atomic-force microscope tips. Rev Sci Instrum 1993;64(7):1868-73.

[37] Sneddon IN. The relation between load and penetration in the axisymmetric Boussinesq problem for a punch of arbitrary profile. Int J Eng Sci; 1965.

[38] Clifford C, Seah M. Quantification issues in the identification of nanoscale regions of homopolymers using modulus measurement via AFM nanoindentation. Appl Surf Sci 2005;252(5):1915-33.

[39] Flores-Merino MVCS, LoPresti C, Reilly C, Battaglia G, Engler AJ. Nanoscopic mechanical anisotropy in hydrogel surfaces. Soft Matter 2010;6(18):4466-70.

[40] Boudou T, Crouzier T, Nicolas C, Ren K, Picart C. Polyelectrolyte multilayer nanofilms used as thin materials for cell mechano-sensitivity studies. Macromol Biosci 2011;11(1):77-89.

[41] Wittmer CR, Phelps JA, Saltzman WM, Van Tassel PR. Fibronectin terminated multilayer films: protein adsorption and cell attachment studies. Biomaterials 2007;28(5):851-60.

[42] Reinhart-King CA, Dembo M, Hammer DA. The dynamics and mechanics of endothelial cell spreading. Biophys J 2005;89(1):676-89.

[43] Marklein RA, Burdick JA. Spatially controlled hydrogel mechanics to modulate stem cell interactions. Soft Matter 2010;6(1):136-43.

[44] Seidlits SK, Khaing ZZ, Petersen RR, Nickels JD, Vanscoy JE, Shear JB, et al. The effects of hyaluronic acid hydrogels with tunable mechanical properties on neural progenitor cell differentiation. Biomaterials 2010;31(14):3930-40.

[45] Erickson IE, Huang AH, Sengupta S, Kestle S, Burdick JA, Mauck RL. Macromer density influences mesenchymal stem cell chondrogenesis and maturation in photocrosslinked hyaluronic acid hydrogels. Osteoarthritis Cartilage 2009; 17(12):1639-48.

[46] Lo CM, Wang HB, Dembo M, Wang YL. Cell movement is guided by the rigidity of the substrate. Biophys J 2000;79(1):144-52.

[47] Liao SW, Yu TB, Guan ZB. De novo design of saccharide-peptide hydrogels as synthetic scaffolds for tailored cell responses. J Am Chem Soc 2009;131(48): 17638-46.

[48] Discher DE, Janmey P, Wang YL. Tissue cells feel and respond to the stiffness of their substrate. Science 2005;310(5751):1139-43.
[49] Yamada KM, Cukierman E. Modeling tissue morphogenesis and cancer in 3D Cell 2007;130(4):601-10.

[50] Choquet D, Felsenfeld DP, Sheetz MP. Extracellular matrix rigidity causes strengthening of integrin-cytoskeleton linkages. Cell 1997; 88(1):39-48.

[51] Takigawa T, Morino Y, Urayama K, Masuda T. Poisson's ratio of polyacrylamide (PAAm) gels. Polym Gels Networks 1996;4(1):1-5.

[52] Frisch SM, Francis H. Disruption of epithelial cell-matrix interactions induces apoptosis. J Cell Biol 1994;124(4):619-26.

[53] Patrucco E, Ouasti S, Vo CD, De Leonardis P, Pollicino A, Armes SP, et al. Surface-initiated ATRP modification of tissue culture substrates: poly(glycerol monomethacrylate as an antifouling surface. Biomacromolecules 2009; 10(11):3130-40.

[54] Lutolf MP, Raeber GP, Zisch AH, Tirelli N, Hubbell JA. Cell-responsive synthetic hydrogels. Adv Mater 2003;15(11):888.

[55] Elbert DL, Hubbell JA. Conjugate addition reactions combined with freeradical cross-linking for the design of materials for tissue engineering. Biomacromolecules 2001;2(2):430-41.

[56] Gobin AS, West JL. Cell migration through defined, synthetic extracellular matrix analogues. FASEB J 2002;16(3):751.

[57] Massia SP, Hubbell JA. Covalently attached GRGD on polymer surfaces promotes biospecific adhesion of mammalian cells. Ann N Y Acad Sci 1990 589:261-70.

[58] Massia SP, Hubbell JA. Covalent surface immobilization of Arg-GlyAsp-containing and Tyr-Ile-Gly-Ser-Arg-containing peptides to obtain well-defined cell-adhesive substrates. Anal Biochem 1990 187(2):292-301.

[59] Lei YG, Gojgini S, Lam J, Segura T. The spreading, migration and proliferation of mouse mesenchymal stem cells cultured inside hyaluronic acid hydrogels. Biomaterials 2011:32(1):39-47.

[60] Ghosh K, Pan Z, Guan E, Ge SR, Liu YJ, Nakamura T, et al. Cell adaptation to a physiologically relevant ECM mimic with different viscoelastic properties. Biomaterials 2007;28(4):671-9.

[61] Kreger ST, Voytik-Harbin SL. Hyaluronan concentration within a 3D collagen matrix modulates matrix viscoelasticity, but not fibroblast response. Matrix Biol 2009;28(6):336-46. 